\title{
Development of highly specific and sensitive PNA-clamp PCR assay for the detection of common mutations (BRAF V600E and NRAS) in CRC using FFPE tissue sample
}

\author{
Reger R.Mikaeel ${ }^{*}$ and Dr. JAMES Howard Pringle ${ }^{* *}$ \\ *Dept. of Biology, College of Science, Kurdistan Region-Iraq \\ *** Dept. of Cancer Studies and Molecular Medicine, University of Leicester-England
}

Received: August 5, 2018, Accepted for publication: October 22, 2018)

\begin{abstract}
Background: Colorectal cancer (CRC) is a frequent and widespread malignancy. Commonly mutated KRAS, BRAF and NRAS genes lead to constant activation of the MAPK pathway; consequently transforming basal stem cells into adenocarcinoma. Selective inhibitors of the MAPK pathway, such as Cetuximab and Panitumumab, have been implemented in clinical practice since 2004. Sanger sequencing and pyro sequencing have been commonly used for detection of BRAF and NRAS mutation in the UK. Nevertheless, sometimes the analytical sensitivity of these methods is not high enough to detect a low percentage of cells containing the mutation. Methods: a highly sensitive and specific Peptide nucelic acide (PNA)-clamp PCR was developed and validated firstly on cell lines that were known to harbour the mutations in $\mathrm{BRAF}^{\mathrm{V} 600 \mathrm{E}}$ or NRAS codons 12 and 13. The wild type and mutant DNA was serially diluted to test the sensitivity of the assay. Total DNA was extracted from 84 formalin fixed paraffin embedded (FFPE) tissues including adenomas, carcinoma and hyperplastic polyps; and screened for $\mathrm{BRAF}^{\mathrm{V} 600 \mathrm{E}}$ or NRAS mutations. Results: the highly sensitive PNA-clamp QUASAqPCR assay significantly detected 1:2000 ratio of mutant to wild type background $(P<0.01)$. The assay on FFPE tissue showed $15.47 \%(13 / 84)$ BRAF $^{\mathrm{V} 600 \mathrm{E}}$ and $8.33 \%(7 / 84) \mathrm{NRAS}$ mutants, of which NRAS c.38G>A (G13D) was the most common. BRAF ${ }^{\mathrm{V} 600 \mathrm{E}}$ mutation was significantly associated to right side tumour $(P<\mathbf{0 . 0 1 4})$, but was not related to any other clinical features. However, there was no significant association between NRAS mutation and any clinicopathological features. Conclusion: this study demonstrates the sensitivity, specificity and utility of PNA-clamp PCR assay in detecting the common point mutations in CRC in a low percentage of cells containing the mutation, providing an attractive tool for future research and therapeutic applications.
\end{abstract}

KEY WORDS: Colorectal cancer, BRAF, NRAS, MAPK pathway, anti-EGFR therapies, PNA and PCR

\section{INTRODUCTION}

W orldwide, it is reported that about 1 million cases are diagnosed with Colorectal Cancer (CRC) annually and approximately, $50 \%$ of them might progress to metastatic disease (Tougeron et al, 2013). It is found that only about 5-33\% of CRCs cases are hereditary and the other $67-95 \%$ are sporadic (Tougeron et al. 2013). BRAF is one of the members of the family of RAF serine-threonine kinases which is an activator of the MAPK pathway. Mutations in theQ1 +0 BRAF gene have been reported in $7 \%-15 \%$ of all human cancers, with melanoma having one of the highest incidences $(40 \%-70 \%)$ and in $12 \%$ of CRC
(Dhomen and Mariase, 2017). This mutation leads to the constitutive activation of the MAPK pathway and increased proliferation, apoptosis, and metastatic potential (Di Nicolantonio et al, 2008). $H-R A S, N-R A S$, and $K-R A S$ are highly homologous proteins that belong to the RAS protein family and all of them have the same first 80 amino acid sequence. RAS family members mediate cellular response to extracellular signals because they act as GDP/GTP-regulated switches (Valtorta et al, 2013). It is known that RAS family members mutated in approximately $20 \%$ of all human tumours. However, KRAS gene is the most common mutated gene of all $R A S$ mutations in human cancers as it accounts for about $85 \%$. It is reported that about $90 \%$ of KRAS mutations are 
found to be in codon 12 and 13 and approximately $5 \%$ in codon 61.In CRC KRAS and NRAS are found to be mutated in approximately $40 \%$ and 1 $6 \%$ of the cases, respectively. Moreover, G>A transitions and $\mathrm{G}>\mathrm{T}$ transversions are the most frequently observed types of $K R A S$ and NRAS mutations (Brink et al, 2003). Over the past 12 years, the treatment of CRC has been significantly progressed. The main treatments are surgery, chemotherapy, radiation therapy and targeted therapy (Douillard et al, 2000). However, EGFR has been clinically and scientifically approved to be the main target for cancer therapy because it is shown to be overexpressed in many human epithelial tumours including CRC. Mutations in $K R A S$ codons 12 and 13 predict a lack of response to the therapy and are also shown to be associated with increased the risk of deaths and recurrence (Tougeron et al, 2013). Furthermore, although wild type $K R A S$ is found to be required, it is not sufficient to confer sensitivity of anti-EGFR. NRAS status, BRAF mutation, PIK3CA mutations, cytoplasmic expression of phosphatase and tensin homologue (PTEN) and EGFR amplification are also found to be associated with the treatment response. Therefore, in addition to KRAS, BRAF, $N R A S$, and PIK3CA exon 20 mutations are also should be detected before treatment (Scaltriti et al, 2006). Testing for mutations in KRAS, NRAS, and $B R A F$ genes is now reported to be essentials for patients with mCRC before treatment with antiEGFR monoclonal antibodies, because mutations in these genes pre dict a lack of response to the therapies (Jonker et al, 2007). Number of molecular biology techniques and methods have been developed for detection of those oncogenic mutations including direct automatic sequencing, pyro sequencing, restriction fragment length polymorphism analysis, single- strand conformation analysis, high-resolution melting analysis a many others (Morlan et al, 2009). Nevertheless, some of these methods are found to be not sensitive enough to detect a low percentage of cells containing the mutation, time consuming and too expensive. Therefore, various alternative methods have recently been developed in order to distinguish wild type from mutant, especially in clinical samples. In this project a highly sensitive and specific allele specific PCR, which is PNA clamp PCR, was developed in order to detect mutations that have potential or actual therapeutic relevance in CRC. The aims of this project were to develop a highly sensitive and specific peptide nucleic acid

(PNA)-clamp PCR for detection of mutations in the NRAS gene codon $12(35 \mathrm{G}>\mathrm{A}(\mathrm{G} 12 \mathrm{D})$ and $34 \mathrm{G}>\mathrm{T}$ (G12C) and codon 13 (38G> A (G13D) as well as the $B R A F$ gene (c.1799 T>A (p.V600E) in samples with a low tumour cell percentage. Moreover, this study was aimed to validate and optimize the assay on cell lines that were harbour to the mutations by designing and using allele specific primers and probes. Additionally, the utility, sensitivity and specificity of the assay were approved by applying on 84 FFPE clinical samples.

\section{MATERIALS AND METHODS \\ Cell lines}

Six human cells lines (MOLT-4, THP-1, NCIH929, SK-MEL5, SK-MEL-28 and 697), were used as positive controls as they are known to harbour relevant mutations. The DNA of cell lines were ordered from the European culture collection (http://www.phe-

culturecollections.org.uk/products/celllines) and have been widely studied.

\section{Samples}

A total of 84 retrospective tissues were obtained from Leicester Royal Infirmary (LRI). These tissues were obtained under the approval of the local ethics community. The tissues have been taken from patients who have adenoma, carcinoma, and from hyperplastic polyps (Table 1). 
Table (1). Clinicopathological characteristics of 84 tumour samples.

\begin{tabular}{cc}
\hline Characteristic & Number (\%) \\
\hline Type and location & \\
\hline Adenomatous right polyp & $10(11.90)$ \\
Adenomatous left polyp & $24(28.57)$ \\
Left carcinoma & $19(22.61)$ \\
Right carcinoma & $23(27.38)$ \\
Right sided hyperplastic polyps & $4(4.76)$ \\
Left sided hyperplastic polyps & $4(4.76)$ \\
\hline Gender & \\
\hline Male & \\
Female & $43(51.19)$ \\
\hline Age & $41(48.80)$ \\
\hline $50-60$ (years) & $14(16.66)$ \\
$60-70$ (years) & $25(29.76)$ \\
$<70$ (years) & $45(53.57)$ \\
\hline
\end{tabular}

\section{MUTATIONS ANALYSIS}

\section{QUASA primers and probes design}

The primer BLAST software (http://www.ncbi.nlm.nih.gov/tools/primer-blast/) was used in order to design primers for quantitative allele specific amplification (QUASA-qPCR). The forward and reverse primers were designed to amplify an NRAS fragment in exon 2, codons 12 and 13 and the resulting amplicon size was $89 \mathrm{bp}$ (Table 2). A free sequence (tag) at the 5'-end terminal of the gene sequence is required for the QUASA primers. Allele specific WT and mutant primers were also designed for amplification of WT and mutant alleles respectively (Table 2). The same software that used for designing primers was used for designing probes as well. Five probes were designed; one of them was away from the mutation for WT and mutant amplification. Furthermore, allele specific wild types and mutant probes were also designed (Table 2 and 4). The reverse primer, forward LNA mutant and wild primers and probe for the $B R A F^{\mathrm{V} 600 \mathrm{E}}$ mutation were already designed and kindly provided by one of the $\mathrm{PhD}$ students. These primers and probe were used for Allele Specific Locked Nucleic Acid Quantitative-PCR (ASLANAqPCR) for the detection of $B R A F^{\mathrm{V} 600 \mathrm{E}}$ mutations. The forward LNA wild type and mutant primers were designed to amplify the wild type and muatnt $B R A F^{\mathrm{V} 600 \mathrm{E}}$; and the resulting amplicon size was 94bp (Table $3)$.

Table (2). Primers and allele specific WT and mutant probes for NRAS codon 12 and 13

\begin{tabular}{ccccc}
\hline Type & \multicolumn{1}{c}{ Probes } & Tm & \%GC & Length \\
\hline $\mathbf{F}$ & 5'-AATGACTGAGTACAAACTGGTGGTG-3' & 58.4 & 44 & 25 \\
\hline $\mathbf{R}$ & 5'-CATCTACAAAGTGGTTCTGGATTAGC-3' & 58.0 & 42 & 26 \\
\hline WT & VIC-TTGGAGCAGGTGGTGTT-MGB & 69.0 & 53 & 17 \\
\hline M34TA & FAM- TTGGAGCAWGTGGTGTT -MGB & 65.0 & 47 & 17 \\
\hline M35A & FAM- TTGGAGCAGATGGTGTT -MGB & 67.0 & 47 & 17 \\
\hline M37C & FAM- TTGGAGCAGGTCGTGTT -MGB & 67.0 & 53 & 17 \\
\hline M38T & FAM- TTGGAGCAGGTGTTGTT -MGB & 69.0 & 47 & 17 \\
\hline
\end{tabular}

$\mathrm{WT}=$ wild type probe, $\mathrm{W}=$ ambiguity code (it means the mutation is either in $\mathrm{T}$ or $\mathrm{A}$ ), FAM= 6-carboxyfluorescein (a fluorophore), $\mathrm{MGB}=$ dihydrocyclopyrroloindole tripeptide minor groove binder (a quencher), $\mathrm{F}=$ forward primer, $\mathrm{R}=$ reverse primer. 
Table (3). primer and probe for $B R A F^{\mathrm{V} 600 \mathrm{E}}$ mutations.

\begin{tabular}{cc}
\hline LNA Primer/Probe & Sequence \\
\hline Forward LNA WT primer & TAGGTGATTTTGGTCTAGCTACAG+T \\
\hline Forward LNA mutant primer & TAGGTGATTTTGGTCTAGCTACAG+A \\
\hline BRAF exon 15 reverse primer & 5'-ATCCAGACAACTGTTCAAACTGATG-3' \\
\hline Probe (away from mutation ) & FAMAATCTCGATGGAGTGGGT-MGB
\end{tabular}

Red= Mutated allele, FAM= 6-carboxyfluorescein (a fluorophore), MGB= dihydrocyclopyrroloindole tripeptide minor groove binder (a quencher), WT= wild type.

Table (4): Probe and allele specific wild type and mutant primers for NRAS codons 12 and 13.

\begin{tabular}{|c|c|c|c|c|c|c|}
\hline \multirow{2}{*}{$\begin{array}{c}\text { Forward } \\
\text { Primer }\end{array}$} & $T \mathrm{~m}$ & $\% G C$ & Length & Sequence & TAG & Length \\
\hline & \multicolumn{3}{|c|}{ PrimerExpress } & & & \\
\hline WT Primer & 59.5 & 57 & 23 & AGTACTAgGGTTGGAGCAGGTGG & AGTACTAG & 15 \\
\hline c.34G>T & 59.1 & 52 & 23 & CAGTACTAcGGTGGTTGGAGCAT & CAGTACTAC & 14 \\
\hline c. $34 \mathrm{G}>\mathrm{A}$ & 60.0 & 52 & 23 & CAGTACTAcGGTGGTTGGAGCAA & CAGTACTAC & 14 \\
\hline$c .34 G>C$ & 59.6 & 57 & 23 & CAGTACTACGGTGGTTGGAGCAC & CAGTACTAC & 14 \\
\hline c. $35 \mathrm{G}>\mathrm{A}$ & 60.0 & 50 & 24 & AAGTACTAcGGTGGTTGGAGCAGA & AAGTACTAC & 15 \\
\hline c.35G $>C$ & 59.8 & 59 & 22 & CTACTAGcGTGGTTGGAGCAGC & CTACTAGC & 14 \\
\hline c.35G $>\mathrm{T}$ & 59.6 & 54 & 24 & GAGTACTAcGGTGGTTGGAGCAGT & GAGTACTAC & 15 \\
\hline c. $37 \mathrm{G}>\mathrm{T}$ & 59.8 & 59 & 22 & AGTACTACAAgGGTTGGAGCAGGTT & AGTACTACAA & 14 \\
\hline c. $.37 \mathrm{G}>\mathrm{C}$ & 59.0 & 57 & 23 & GAGTACTAcGGTTGGAGCAGGTC & GAGTACTAC & 14 \\
\hline c.38G $>C$ & 58.2 & 54 & 24 & GAGTACTACaGTTGGAGCAGGTGC & GAGTACTACA & 14 \\
\hline c.38G $>A$ & 59.7 & 54 & 24 & GAGTACTAgGGTTGGAGCAGGTGA & GAGTACTAG & 15 \\
\hline c.38G $>\mathrm{T}$ & 58.8 & 54 & 24 & GAGTACTAgGGTTGGAGCAGGTGT & GAGTACTAG & 15 \\
\hline c.34_38P & 68 & 44 & 14 & FAM-AAAGCGCACTGACAAT-MGB & & \\
\hline
\end{tabular}

$\mathrm{WT}=$ wild primer, $\mathrm{red}=$ tag sequence, yellow= mutant alleles. FAM= 6-carboxyfluorescein $($ a fluorophore), MGB= dihydrocyclopyrroloindole tripeptide minor groove binder (a quencher). $\mathrm{VIC}=$ a fluorophore dye. $\mathrm{P}=$ probe.

\section{Designing PNA probes for PNA clamp PCR}

The http://pnabio.com/support/PNA_Tool.htm website was used to design the PNA probe for NRAS mutations in codons 12 and 13. The PNA probe for $B R A F$ V600E muatioons were already designed and provided by one of the $\mathrm{PhD}$ students
(5' TAGCTACAGTGAAATC 3'). The temperature, $\mathrm{G} / \mathrm{C}$ content and length of the PNA probe were checked and optimised by using the primer express 3.0 software (applied Biosystems, Cheshire, UK). 


\section{DNA extraction from FFPE tissue}

DNA was extracted from 84 FFPE tisssues to analyse mutations in KRAS and NRAS condons 12 and 13 as well as $B R A F^{\mathrm{V} 600 \mathrm{E}}$. The samples were incubated for 5 minutes at $65^{\circ} \mathrm{C}$ in order to melt the wax and then dewaxed in Xylene ( 3 minutes $\mathrm{x}$ 2 ) and put in alchohols $99 \%$ ( 1 minute $x$ 1) $95 \%$ (1 minute $\mathrm{x} 1)$. After the slides had been dried in air, the sections were scraped off into $100 \mu l$ buffer ATL, transferred to $1.5 \mathrm{ml}$ eppenddorf and then the slides were rinsed with a furthere $100 \mu \mathrm{l}$ buffer ATL. The samples were vortexted well and incubated at $56^{\circ} \mathrm{C}$ for up to 48 hours with proteinase $\mathrm{K}(10 \mu \mathrm{lof} 10 \mathrm{mg} / \mathrm{ml})$. The mixture were transferred to $0.5 \mathrm{ml}$ safe locked tubes and incubated at $70^{\circ} \mathrm{C}$ for 10 minutes in a DNA thermal cycler (Perkin Elmer/Cetus 480; Perkin Elmer, Norwalk, CT). The samples were transferred to $1.5 \mathrm{ml}$ eppedorfs , $200 \mu \mathrm{l}$ of absolute ethanol added and mixed well by vortexing. The samples were applied to a QIAamp column and centerifuged at $8000 \mathrm{rpm}$ for one minute. After the samples was transferred to a fresh collection tube and washed with $500 \mu 1$ buffer AW1, the samples were centerfuged for another minute at 8000rpm. The QIAamp spin column was transferred to a fresh collection tube and $500 \mu 1$ of buffer AW2 was added. The spin column was centrifuged at $14000 \mathrm{rpm}$ for 3 minutes, placed in a fresh collection tube and centerifuged for another minute at the same speed. Then, samples were trasnferred to new collection tube and $35 \mu \mathrm{l}$ of elutiion buffer(AE) was added. Finally, the coulnm was centerifuged at $8000 \mathrm{rpm}$ for one minute after incubation at room temperature for 5 minutes. DNA was quantified using the Nanodrop spectrphotometer (ND-100 Technologies, V3.2.1, USA) and the extracted DNA was stored at $4^{\circ} \mathrm{C}$.

\section{Real Time quantitative Polymerase Chain Reaction (Real-Time qPCR)}

Real Time quabtitative Polymerase Chain Reaction (Real-Time qPCR) reactions were performed by using StepOne Plus Applied Biosystems Real-time PCR (Applied Biosystems, USA). The primers were concentrated to $200 \mathrm{pmol} / \mu \mathrm{l}$ by adding appropriate volume of sterile ultrapure water (UP). The primers were diluted $1: 10$ by adding $10 \mu \mathrm{l}$ of the primer stock into $90 \mu \mathrm{l}$ of UP water. The same steps were done for diluting the PNA. Probes were diluted 1:50 by adding $2 \mu \mathrm{l}$ of probe into $98 \mu \mathrm{l}$ of UP water. DNA from cell lines and clinical samples were also diluted by adding appropriate volume of the UP water. Reactions containing $10 \mathrm{ng} / 3 \mu \mathrm{l}$ of genomic FFPE DNA were distributed into duplicate wells in a 96-well plate. Moreover, each plate included no template controls and positive controls. the assay was carried out in $10 \mu \mathrm{l}$ reaaction mixture containg $5 \mu$ of TaqMan Genotyping Master Mix (Applied Biosystems, cat.no: 4371355, Cheshire, UK), primers, probes and PNA (0.2 $\mu \mathrm{l}$ each), $3 \mu \mathrm{l}$ DNA and the sterile UP water was used to make the final volume $10 \mu 1.7 \mu 1$ of the the master mix was distributed to the 96 well plates and then $3 \mu 1$ $(10 \mathrm{ng} / 3 \mu \mathrm{l})$ of DNA was added to them. StepOne Plus Applied Biosystems Real-time PCR (Applied Biosystems, USA) was used in the standard mode running ( 2 hours) to maplify the PCR amplicons. Touch down QUASAqPCR method was used to increase the specificty of the primers and probes. The temperature for the initial 10 cycles was at $69^{\circ} \mathrm{C}$. The temperature was decreased in increments for the followed cycles until $62^{\circ} \mathrm{C}$ for probes and $61^{\circ} \mathrm{C}$ for primers.

\section{RESULTS}

Initially, Catalogue of Somatic Mutations in Cancer (COSMIC) was used to find the most frequently occurring mutations in CRC (https://cancer.sanger.ac.uk/cosmic). It was observed that APC, KRAS, BRAF and NRAS genes are commonly mutated in CRC. According to the COSMIC website, the frequency of KRAS, BRAF and NRAS mutations in CRC is $40 \%$, $10.69 \%$ and $4.22 \%$, respectively. However, approximately, $95.3 \%$ of BRAF mutations is BRAF c.1799T >A (V600E). In terms of NRAS, the data suggests that NRAS c.34G $>$ T (G12C), NRAS c.35G>A (G12D) and NRAS c.38G>A (G13D) mutation are the most commonly occurring mutation in CRC .

\section{The specificity and selectivity of probes for qPCR}

The specificity and selectivity of allele specific probes for qPCR were evaluated on cell lines. Both the 697 and THP-1 cell lines are heterozygous for the NRAS G12D mutation whereas MOLT-4 and NCI-H929 are heterozygous for the NRAS G12C and NRAS G13D mutations, respectively. WT human genomic DNA (without mutation) was used to calibrate the WT probe. It was found that only WT probe, but not mutant probe was amplified with human genomic DNA (HGDNA) and 
unexpectedly with 697 cell lines (table 5 and figure 1). The other heterozygous cell lines (THP1 and NCI-H929) produced amplified products for both the WT and mutant probes. The WT DNA was amplified at 25 threshold cycle $(\mathrm{Ct})$ (table 5 and figure 1). The specificity and sensitivity of probes were determined by looking at the delta $\mathrm{Ct}$ $(\Delta \mathrm{Ct})(\Delta \mathrm{Ct}=\mathrm{MUT} \mathrm{Ct}$ mean $-\mathrm{WT} \mathrm{CT}$ mean $)$. The
$\Delta \mathrm{Ct}$ was shown to be $1.80,1.27$ and -0.52 for MOLT-4, NCI-H929 and THP-1, respectively (Table 5). Moreover, no PCR products were found with water which was used as negative control. These results show that the probes were specific to $N R A S$ as they were working properly on all cell lines except with 697 cell line (Table 5 and figure $1)$.

Table (5): qPCR using WT and MUT probes. it demonstrates the threshold cycles and $\Delta \mathrm{Ct}$ values of the cell lines and HGD.

\begin{tabular}{|c|c|c|c|c|}
\hline Samples & Probe & WT Ct mean & MUT Ct mean & $\Delta \mathrm{Ct}$ \\
\hline \multirow[t]{4}{*}{ HGDNA } & NRAS c.34G>T (G12C) & 25.79 & $<50$ & 24.21 \\
\hline & & & $<50$ & \\
\hline & NRAS c.35G>A (G12D) & 26.23 & $<50$ & 23.77 \\
\hline & NRAS c.38G>A (G13D) & 24.81 & & 25.19 \\
\hline MOLT-4 & NRAS c.34G>T (G12C) & 25.64 & 27.45 & 1.80 \\
\hline 697 & NRAS c.35G>A (G12D) & 25.93 & $<50$ & 24.07 \\
\hline NCl-H929 & NRAS c.38G>A (G13D) & 25.53 & 26.81 & 1.27 \\
\hline THP-1 & NRAS c.35G>A (G12D) & 25.25 & 24.73 & -0.52 \\
\hline
\end{tabular}



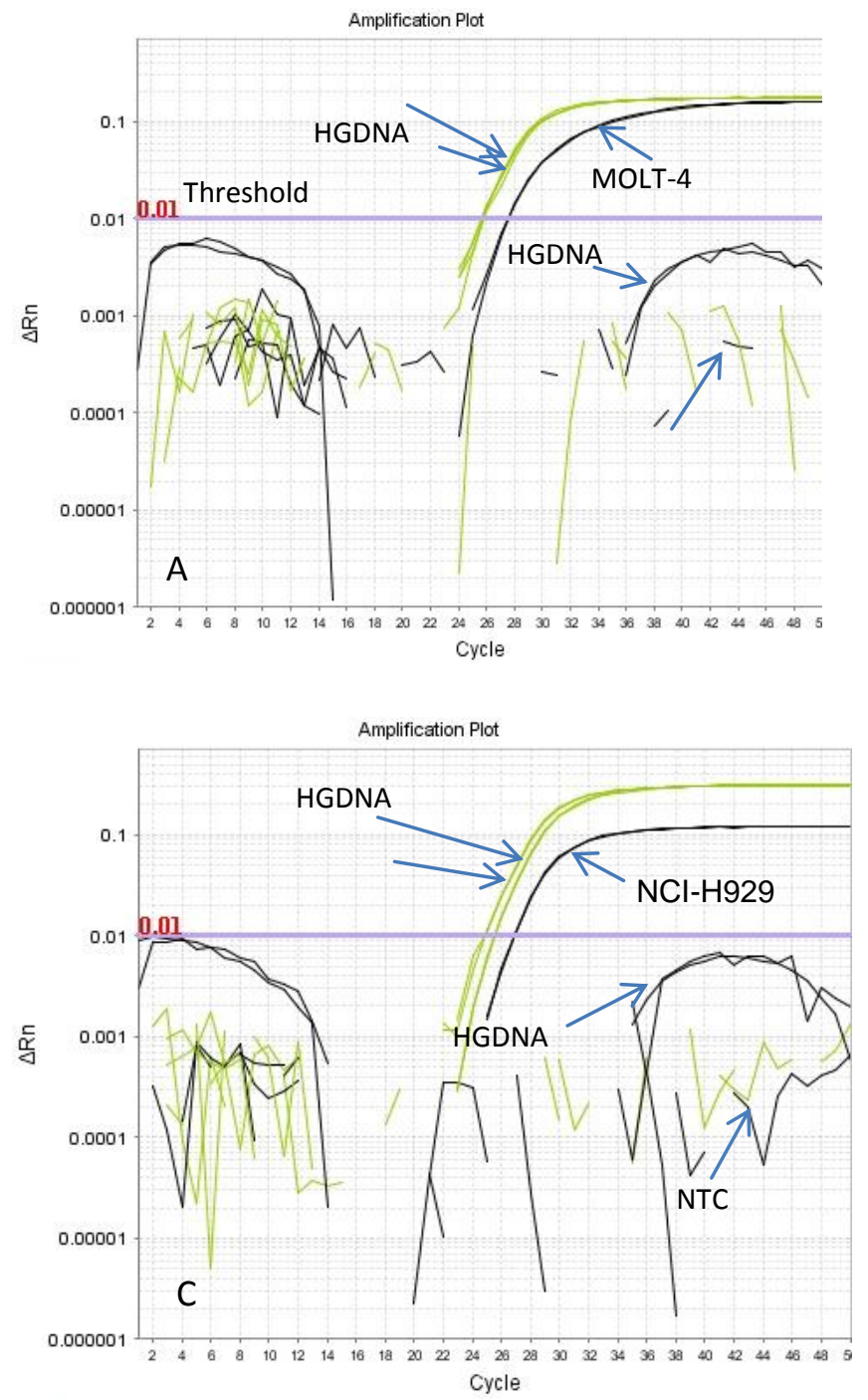
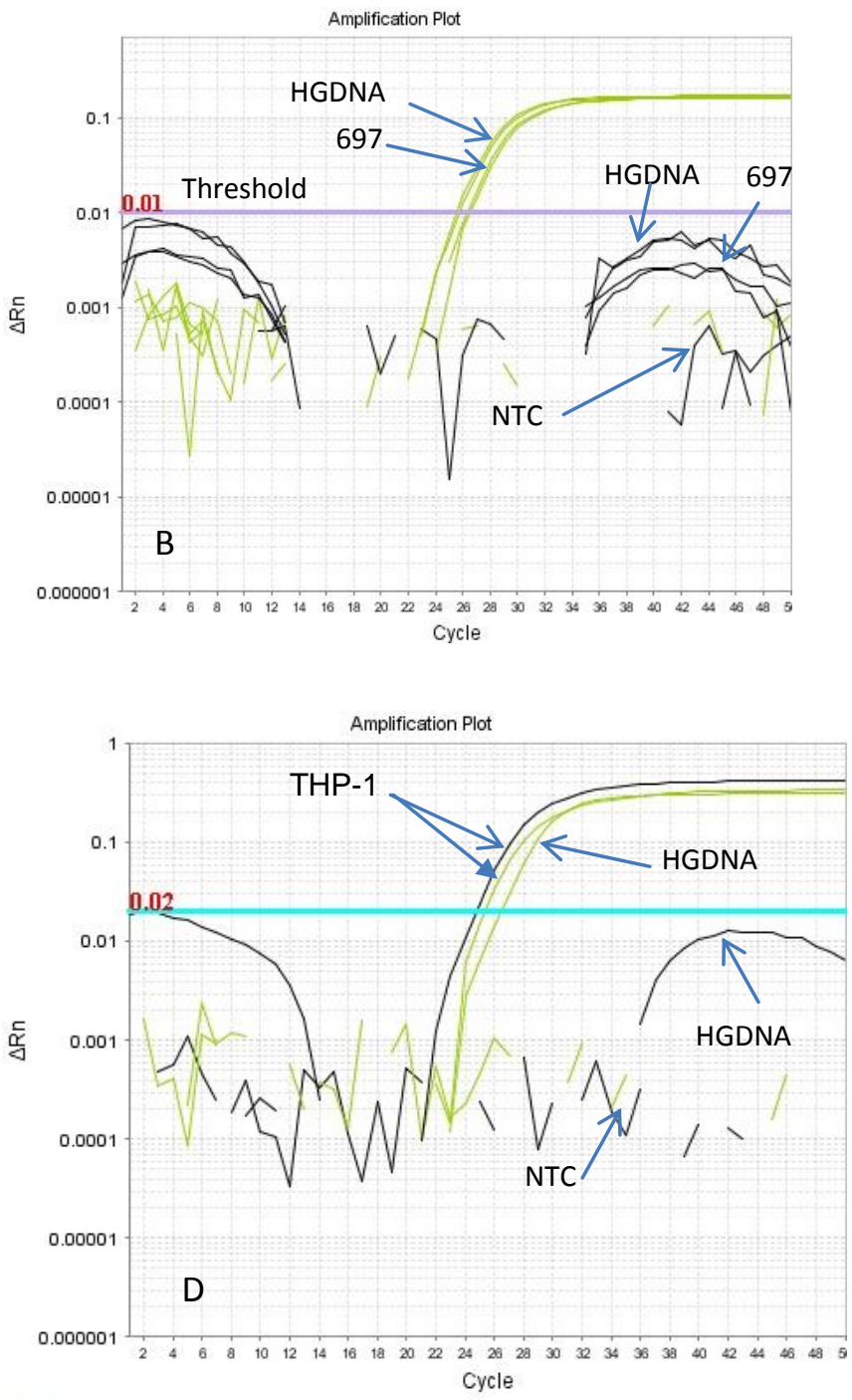

Fig. (1): Specificity and selectivity of allele specific WT and MUT probes. A. Amplification plot of NRAS c.34G>T (G12C) probe versus cycle number showing the specificity of of qPCR WT and MUT allele specific probes. B. Amplification plot of NRAS c.35G>A (G12D) probe versus cycle number showing the specificity of of qPCR WT and MUT allele specific probes. C. Amplification plot of $N R A S$ c.38G>A (G13D) probe versus cycle number showing the specificity of of qPCR WT and MUT allele specific probes. D. Amplification plot of NRAS c.35G>A (G12D) probe versus cycle number showing the specificity of of qPCR WT and MUT allele specific probes. Black= mutant probe, green $=\mathrm{WT}$ probe, $\mathrm{NTC}=$ non template controls (water).

\subsection{Specificity and selectivity of primers for qPCR}

It was observed that the WT DNA was not quantified or quantified at very high $\mathrm{Ct}$ with the mutation specific primers. However, it was quantified at low Ct (29.44) with the WT-specific primers (figure 2 and table 6). The mutant DNA that was extracted from MOLT-4, NCI-H929 and THP-1 cell lines was quantified with the mutation specific primers and with WT-specific primers (Figure 2 and table 6). The $\Delta \mathrm{Ct}$ for heterozygous
MOLT-4, NCI-H929 and THP-1cell lines was 2.26, 1.18 and 0.72 , respectively. The DNA that was extracted from 697 cell line was quantified with WT-specific primers at considerably lower $\mathrm{Ct}$ in comparison to their quantifications with the mutation specific primers. The $\Delta \mathrm{Ct}$ for 697 cell line was 5.95 (Table 6). Furthermore, there were no PCR products with water (negative control) indicating that the primers were specific to NRAS gene

(Figure

2). 
Table 6. qPCR using WT and MUT primers. The table demonstrates the threshold cycles and $\Delta \mathrm{Ct}$ values of the cell lines and HGD.

\begin{tabular}{ccccc}
\hline Sample & Mutation & WT Ct mean & MUT Ct mean & $\Delta$ Ct \\
\hline $\begin{array}{l}\text { HGDNA } \\
\text { HGDNA }\end{array}$ & NRAS c.34G>T(G12C) & 29.44 & $<50$ & 20.56 \\
& NRAS c.35G $>$ A (G12D & 29.44 & $<48 . .25$ & 18.81 \\
& NRAS c.35G>A (G12D & 29.44 & $<50$ & 20.56 \\
\hline MOLT-4 & NRAS c.34G>T (G12C) & 29.51 & 31.77 & 5.95 \\
\hline 697 & NRAS c.35G>A (G12D & 25.93 & 31.88 & 1.18 \\
\hline NCl-H929 & NRAS c.38G>A (G13D) & 31.55 & 32.73 & 0.72 \\
\hline THP-1 & NRAS c.35G>A (G12D & 29.96 & 30.68 & \\
\hline
\end{tabular}

\section{Specificity and selectivity of PNA clamp on cell lines}

PNAs are artificially synthesized oligonucleotide analogues in which the sugar phosphate backbone is replaced by a pseudopeptide backbone. The clamp was designed to effectively target the point mutations and to block wild type DNA from competing in the PCR as a template (Figure 2 and figure 3). PNA-clamp PCR technique was used in different ways in order to understand the concept of this novel method for detection of point mutations. PNA was designed to hybridize with the WT alleles of the NRAS gene codons 12 and 13 and block their amplifications. Therefore, only mutant alleles were expected to amplify (Figure 2 and 3). The sensitivity and specificity of PNA-clamp PCR technique was tested with three cell lines (MOLT-4, THP-1 and
NCI-H929) as they were harbour to NRAS codons 12 and 13 mutations and with HGDNA. PNA was used with both mutation allele specific primers and probes but it was not used with the WT allele specific primers and probes. It was shown that with the MUT allele specific primers or probes + PNA; the Ct of the WT DNA was undetermined or sometimes was quantified at very high $\mathrm{Ct}$ (Figure 4 and 5) While with the WT allele specific primers or probes - PNA; the WT DNA the WT DNA was quantified at low Ct. Conversely, PNA did not block the amplification of MUT DNAs as they were amplified in both MUT allele specific primers and probes (table 7 and 8 , figure 4 and 5). These results show that the PNA was specific for blocking the amplification of WT DNA in NRAS $\begin{array}{llll}\text { codons } & 12 & \text { and }\end{array}$ 

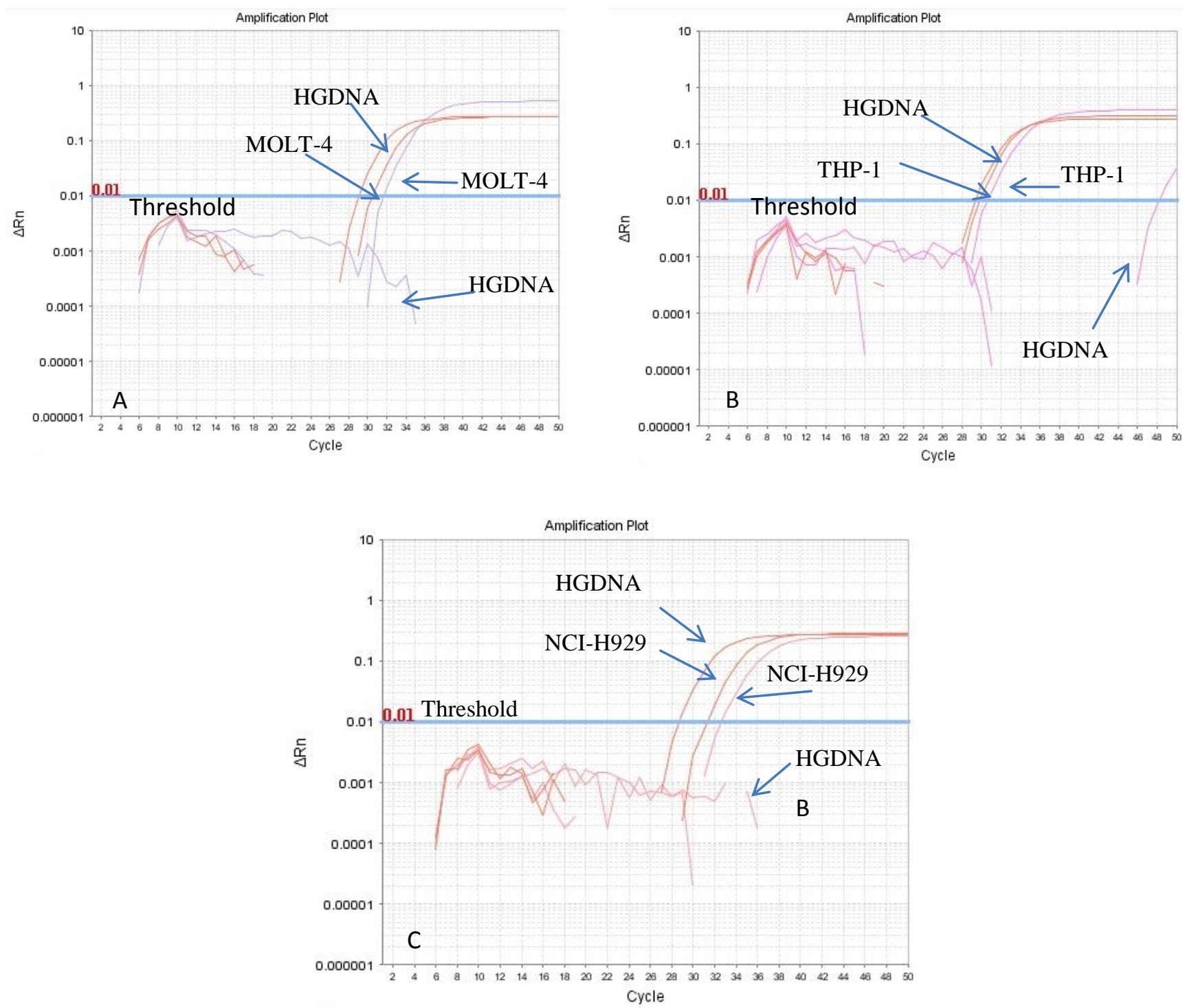

Fig. (2). Specificity and selectivity of allele specific WT and MUT primers. A. Amplification plot of NRAS c.34G $>\mathrm{T}$ (G12C) probe versus cycle number showing the specificity of of qPCR WT and MUT allele specific primers. B. Amplification plot of NRAS c.35G>A (G12D) primer versus cycle number showing the specificity of of qPCR WT and MUT allele specific primers. C. Amplification plot of $N R A S$ c.38G>A (G13D) primer versus cycle number showing the specificity of of qPCR WT and MUT allele specific primers. Purple $=$ mutant probe, Orange $=$ WT primer. 

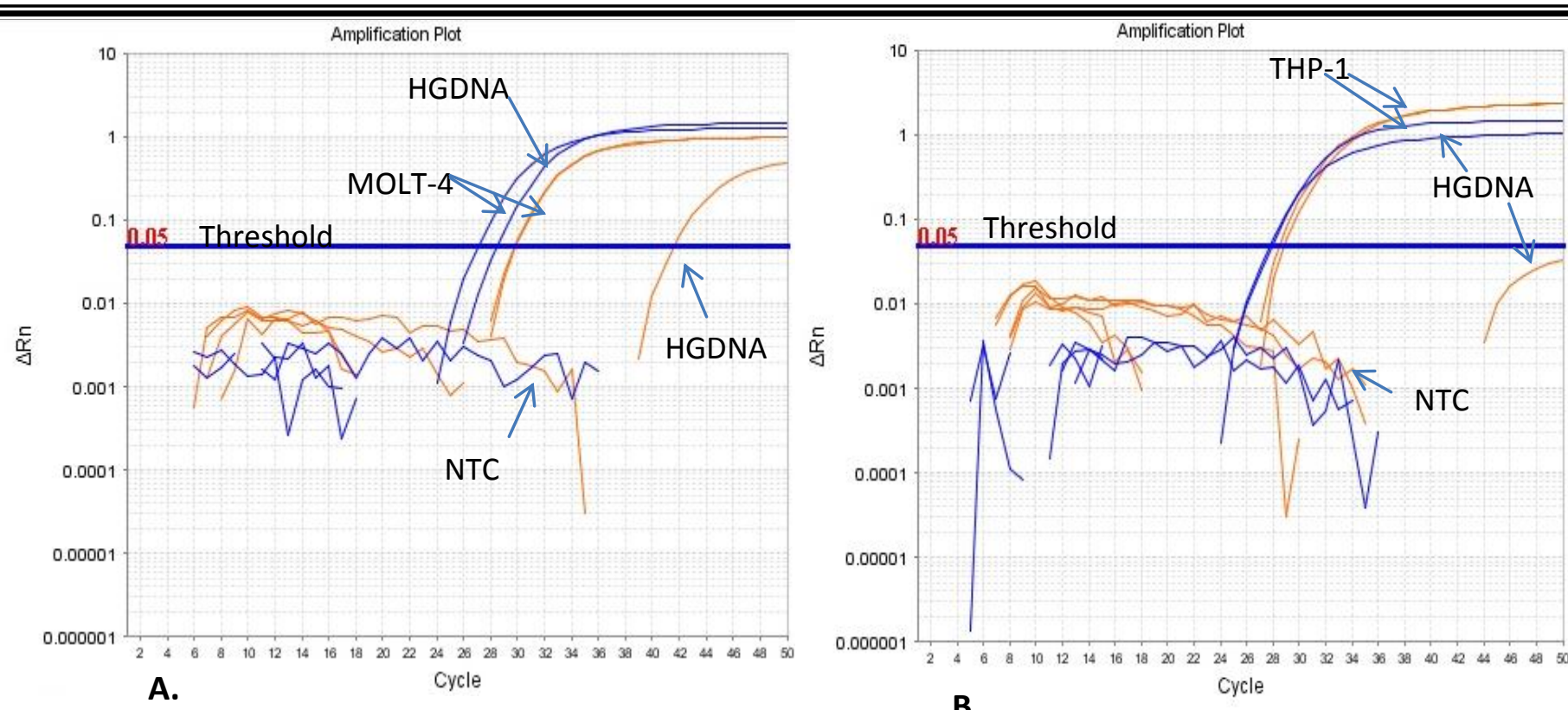

A.

B.

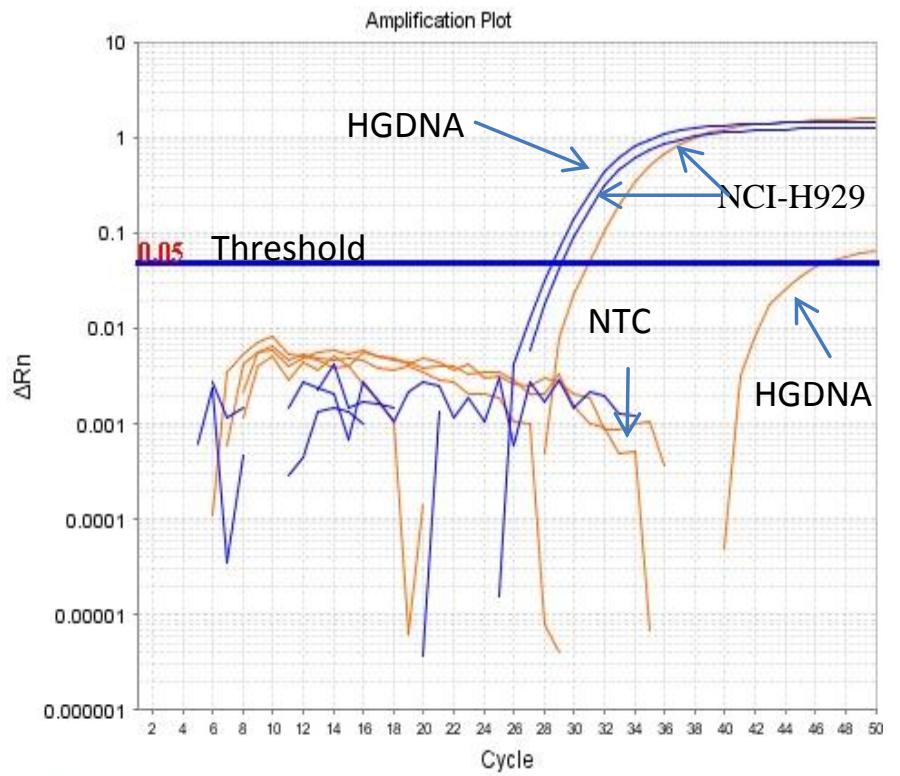

Fig. (3). Specificity and selectivity of PNA clamp on cell lines and HGDNA by using WT and MUT allele specific probes. A. Amplification plots of NRAS c.34G>T (G12C) and HGDNA fluorescence versus cycle number shows the specificity of PNA clamp on MUT and WT DNA. B. Amplification plots of NRAS c.35G>A (G12D) and HGDNA fluorescence versus cycle number shows the specificity of PNA clamp on MUT and WT DNA. C. Amplification plots of NRAS c.38G>A (G13D) and HGDNA fluorescence versus cycle number shows the specificity of PNA clamp on MUT and WT DNA. Orange $=$ with PNA, blue $=$ without PNA. HGDNA= human genomic DNA, NTC= non template control. 

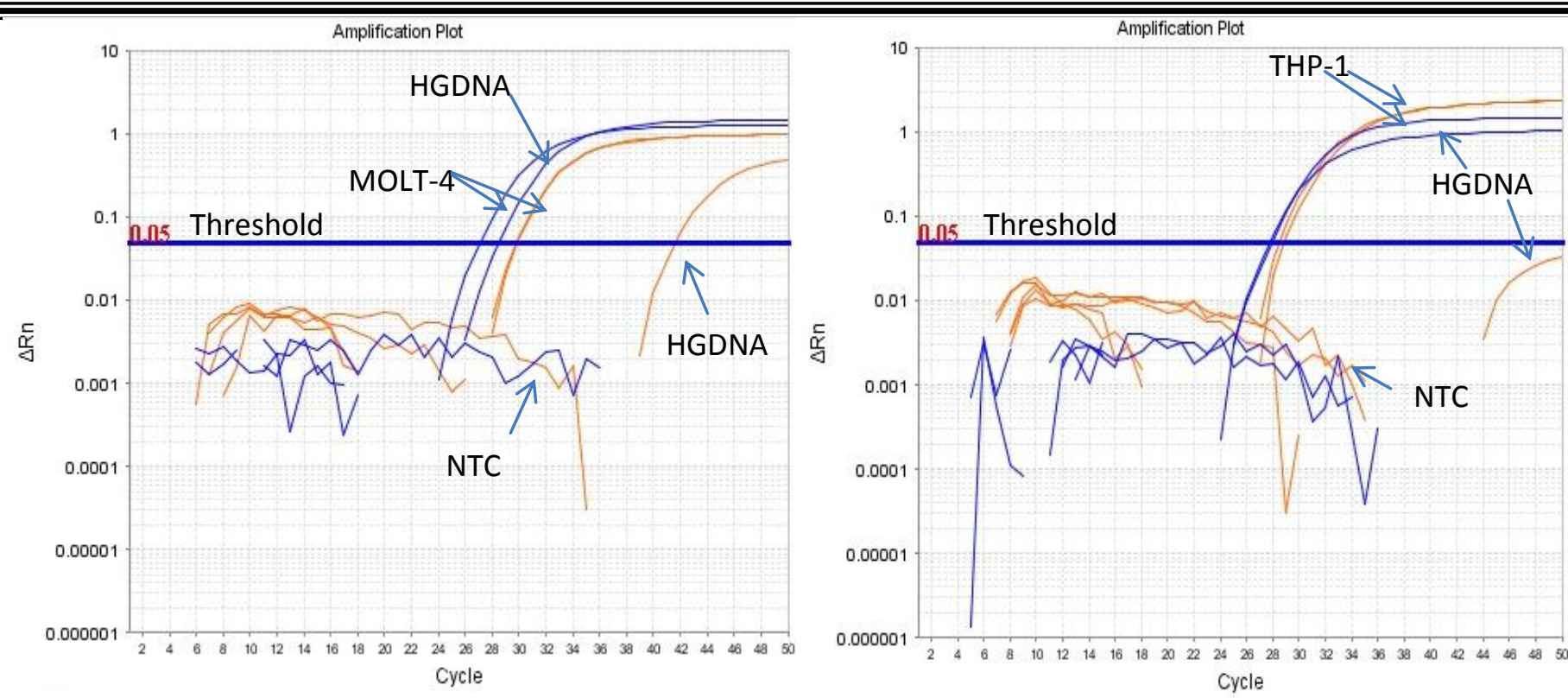

A.

C.

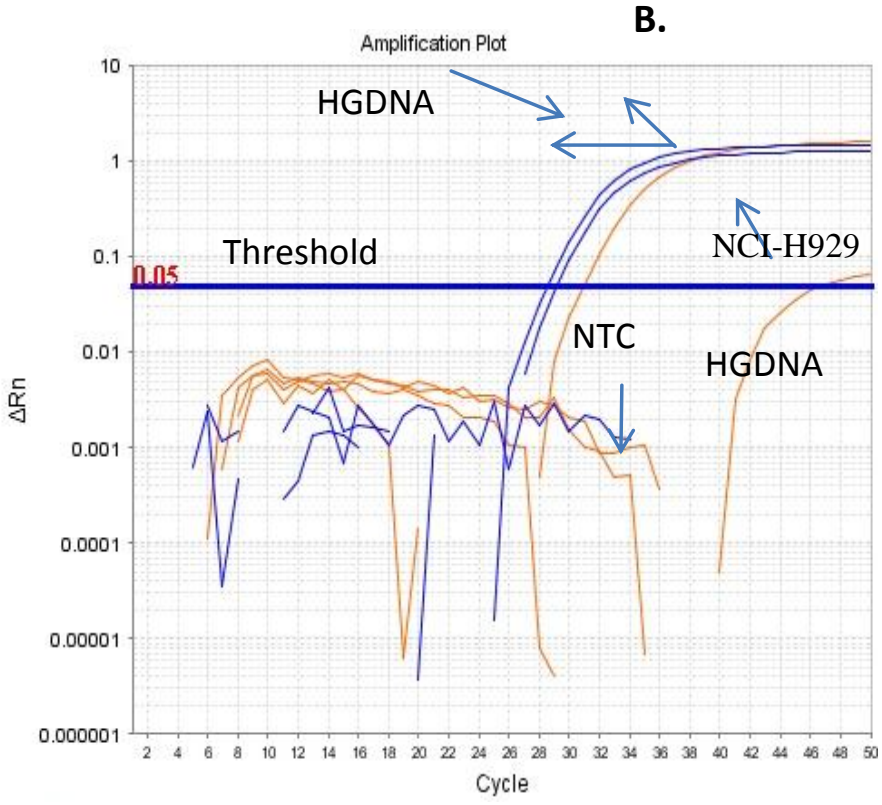

Fig. (4): Specificity and selectivity of PNA clamp on cell lines and HGDNA by using WT and MUT allele specific probes. A. Amplification plots of NRAS c.34G>T (G12C) and HGDNA fluorescence versus cycle number shows the specificity of PNA clamp on MUT and WT DNA. B. Amplification plots of NRAS c.35G>A (G12D) and HGDNA fluorescence versus cycle number shows the specificity of PNA clamp on MUT and WT DNA. C. Amplification plots of $N R A S$ c.38G $>\mathrm{A}(\mathrm{G} 13 \mathrm{D})$ and HGDNA fluorescence versus cycle number shows the specificity of PNA clamp on MUT and WT DNA. Orange = with PNA, blue $=$ without PNA. HGDNA= human genomic DNA, NTC= non template control. 


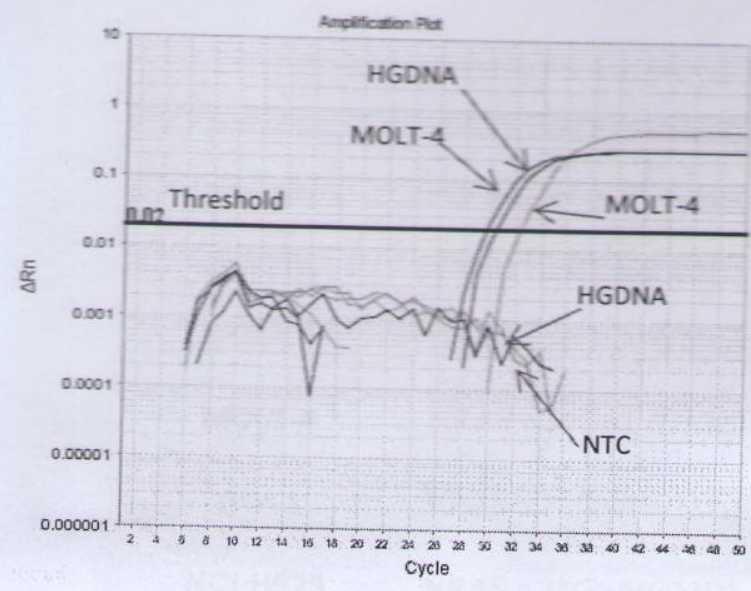

A.

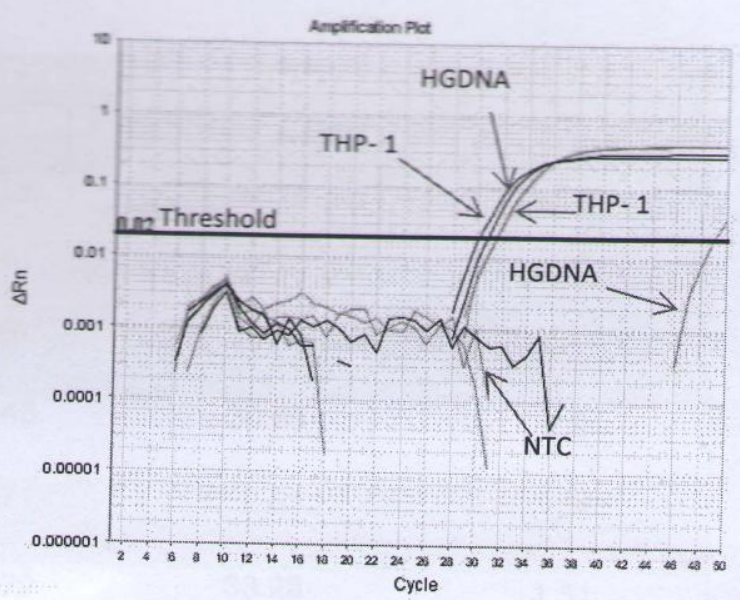

B.

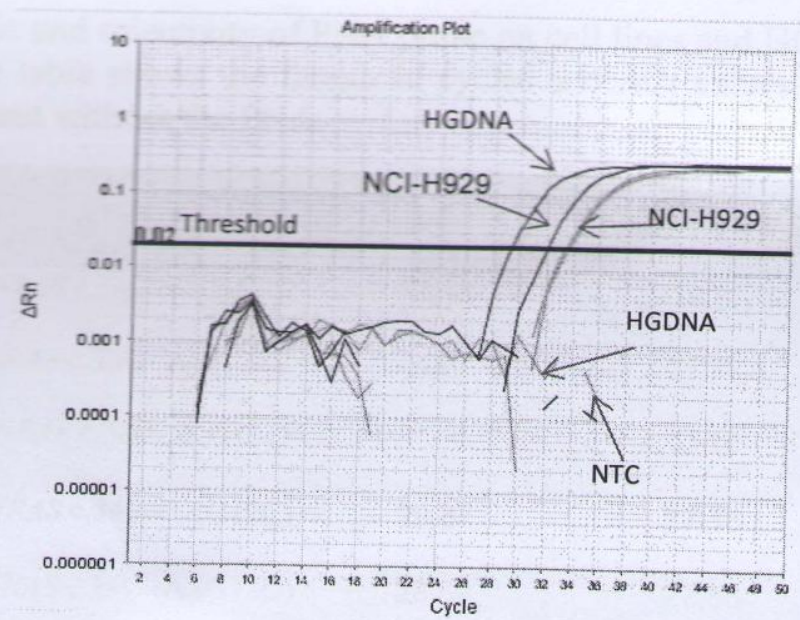

C.

Fig. (5). Specificity and selectivity of PNA clamp on cell lines and HGDNA by using allele specific primers. A. Amplification plots of NRAS c.34G>T (G12C) and HGDNA fluorescence versus cycle number shows the specificity of PNA clamp on MUT and WT DNA. B. Amplification plots of NRAS c.35G>A (G12D) and HGDNA fluorescence versus cycle number shows the specificity of PNA clamp on MUT and WT DNA. C. Amplification plots of NRAS c.38G>A (G13D) and HGDNA fluorescence versus cycle number shows the specificity of PNA clamp on MUT and WT DNA. Orange = with PNA, blue $=$ without PNA. HGDNA= human genomic DNA, NTC= non template control. 
Table (7): The specific and selectivity of PNA on cell lines and HGDNA by using allele specific primers. The table shows the threshold cycles and $\Delta \mathrm{Ct}$ values of the WT DNA and mutant DNAs with and without the PNA.

\begin{tabular}{ccccc}
\hline Samples & \multicolumn{1}{c}{ Primer } & $\begin{array}{c}\text { MUT Ct mean+ } \\
\text { PNA }\end{array}$ & WT Ct mean - PNA & ACt \\
\hline HGDNA & NRAS c.34G>T (G12C) & $<50$ & 31.18 & 18.82 \\
HGDNA & NRAS c.35G>A(G12D) & $<50$ & 30.89 & 19.11 \\
HGDNA & NRAS c.38G>A(G13D) & $<50$ & 29.56 & 2.44 \\
\hline MOLT-4 & NRAS c.34G>T (G12C) & 33.45 & 30.65 & -0.9 \\
\hline THP-1 & NRAS c.35G>A(G12D) & 31.71 & 32.61 & 1.51 \\
\hline NCl-H929 & NRAS c.38G>A(G13D) & 34.79 & 33.28 & \\
\hline
\end{tabular}

Table (8): The specific and selectivity of PNA probe on cell lines and HGDNA by using allele specific probes. The table shows the threshold cycles and $\Delta \mathrm{Ct}$ values of the WT DNA and mutant DNAs with and without the PNA.

\begin{tabular}{ccccc}
\hline Samples & Mutation & $\begin{array}{c}\text { MUT Ct mean + } \\
\text { PNA }\end{array}$ & WT Ct mean - PNA & $\Delta$ Ct \\
\hline HGDNA & NRAS c.34G>T (G12C) & 40.60 & 28.77 & 15.84 \\
HGDNA & NRAS c.35G >A(G12D) & $<50$ & 28.14 & 21.86 \\
HGDNA & NRAS c.38G>A(G13D & $<50$ & 28.12 & 2.72 \\
\hline MOLT-4 & NRAS c.34G>T (G12C) & 29.87 & 27.15 & 0.84 \\
\hline THP-1 & NRAS c.35G>A (G12D) & 28.69 & 27.85 & 1.58 \\
\hline NCI-H929 & NRAS c.38G $>$ A (G13D) & 31.02 & 29.44 & \\
\hline
\end{tabular}

\section{Analytical sensitivity of PNA-clamp QUASAqPCR}

DNA from the NRAS c.38G>A (G13D) mutated NCI-H929 cell line was serially diluted into the WT DNA from the HGDNA in order to perform analytical sensitivity of the PNA-clamp QUASAqPCR. Additionally, triplicates of sterile UP water and WT DNA (0\% mutant) were also included in this test as a negative control and as a reference, respectively. PNA was added to the reaction with the mutation allele specific probe, but it was not added with the WT allele specific probe. It was observed that with the WT allele specific probe, all the dilutions of DNA were amplified almost at the same $\mathrm{Ct}$ (figure 7). Moreover, no amplification of water was observed in the reactions indicating that there was no contamination. However, with the mutant NRAS c.38G>A (G13D) probe; WT DNA (0\%mutant) was quantified at the very high $\mathrm{Ct}$ (39.69), but all the concentration of the mutant DNA were amplified starting from low $\mathrm{Ct}$ (29.40) to high $\mathrm{Ct}$ (38.11) with the mutation allele specific probe and PNA (figure 3.8.). The $\Delta \mathrm{Ct}$ of the $25 \%, 12.5 \%, 6.5 \%, \quad 3.125 \%, \quad 1.562 \%, \quad 0.78 \%$, $0.39 \%, 0.19 \%, 0.09 \%$, and $0.04 \%$ mutant DNA was $-10.29,-9.60,-8.94,-7.47,-6.30,-5.89,-4.43$, $-4.39,-3.22$ and -2.54 , respectively. It was observed that even $0.04 \mathrm{ng}$ of mutated DNA can be detected among the high background of WT DNA by the using PNA-clamp QUASAqPCR assay $(\mathrm{P}<$ 0.01) (figure

$6)$. 


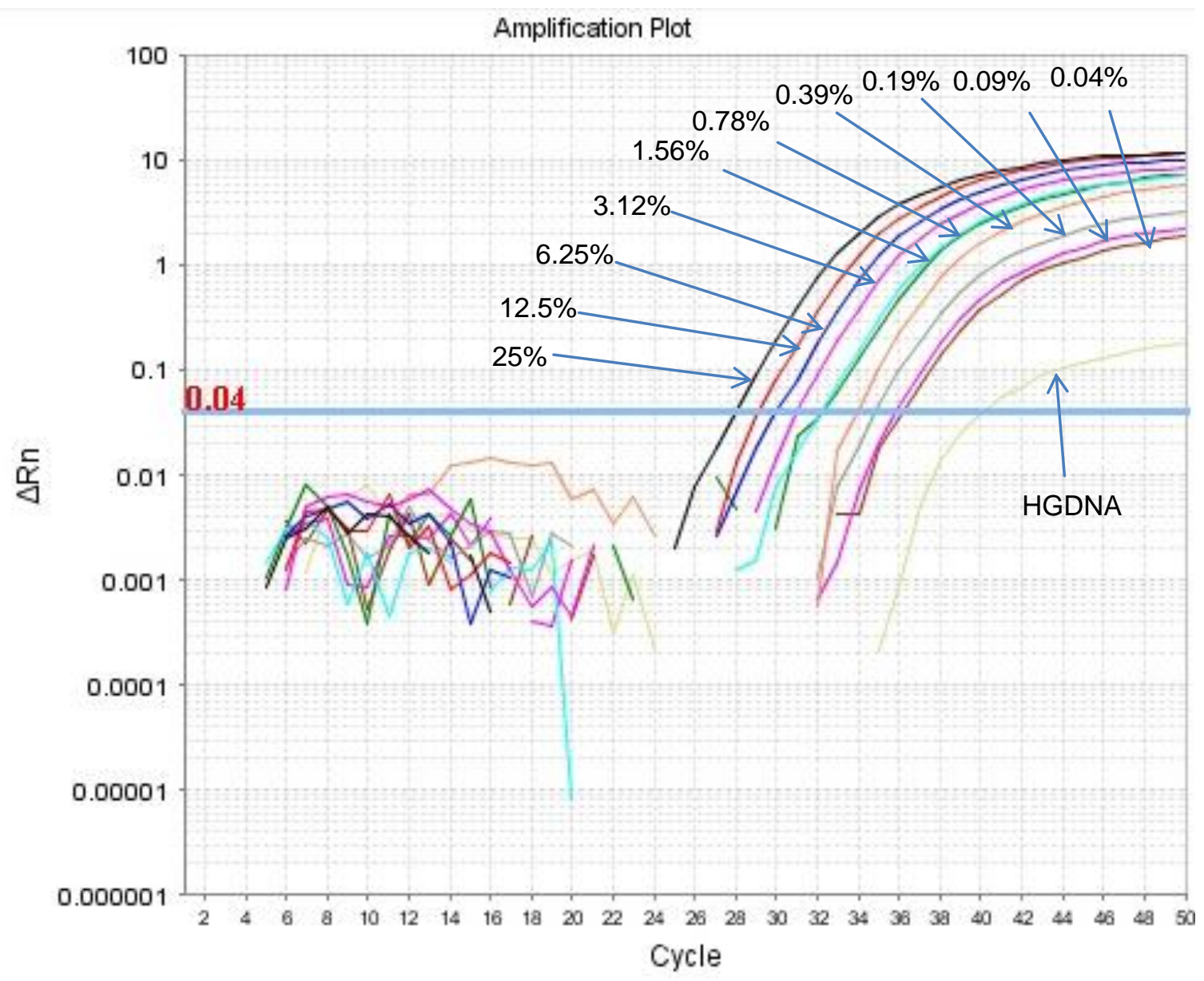

Fig. (6): Analytical sensitivity of PNA-clamp QUASAqPCR. The figure shows amplification plot obtained for WT DNA and sample containing known amount of NRAS c.38G > A (G13D) mutated alleles $(25 \%, 12.5 \%, 6.25 \%$, $3.125 \%, 1.56 \%, 0.78 \%, 0.39 \%, 0.19 \%$ and $0.09 \%, 0.04)$ to WT DNA background by using mutant NRAS c.38G $>$ A (G13D) probe. HGDNA= human genomic DNA. 


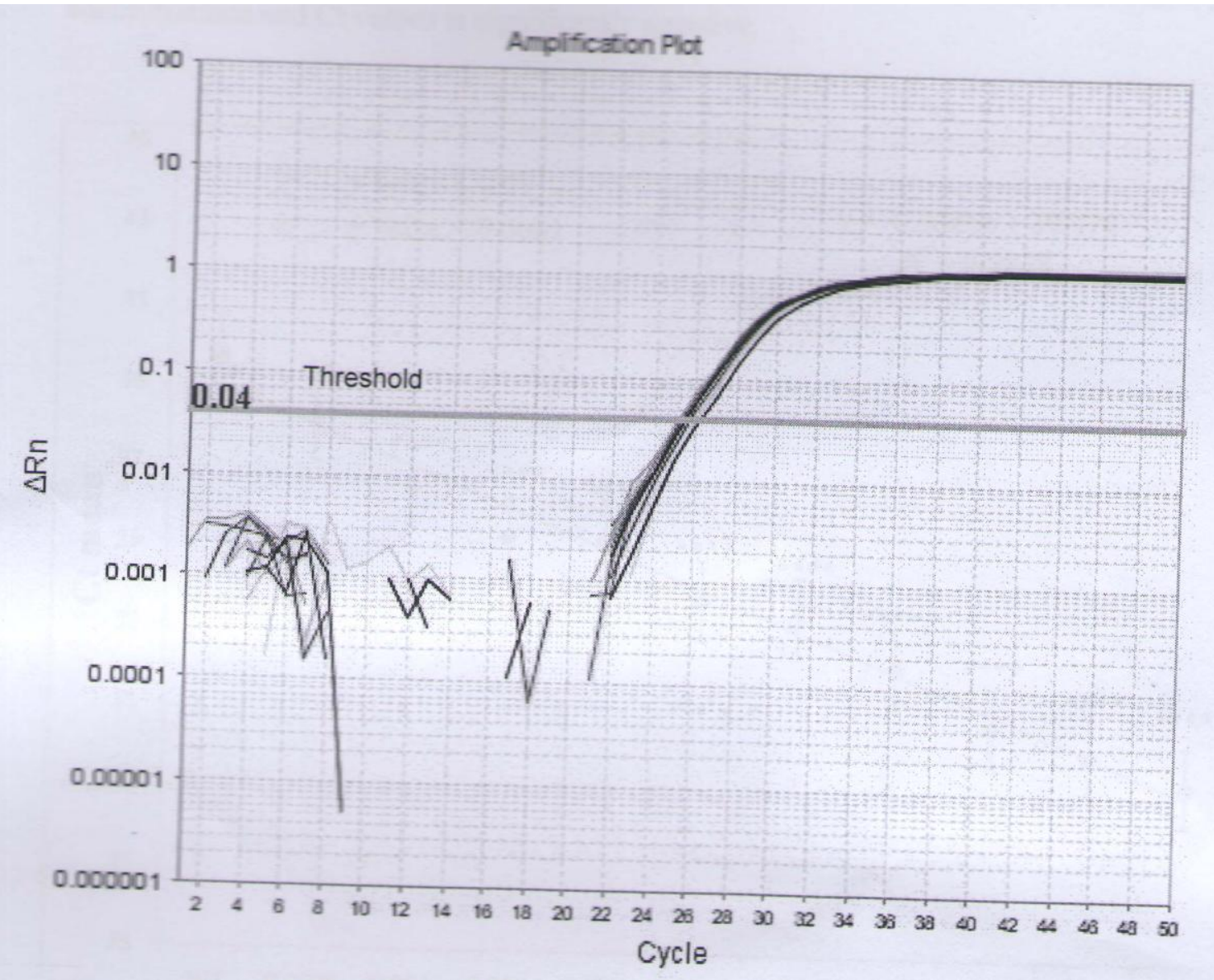

Figure 7. Analytical sensitivity of PNA-clamp QUASAqPCR. The figure shows amplification plot obtained for WT DNA and sample containing known amount of $N R A S$ c.38G $>$ A (G13D) mutated alleles $(25 \%, 12.5 \%, 6.25 \%$, $3.125 \%, 1.56 \%, 0.78 \%, 0.39 \%, 0.19 \%$ and $0.09 \%, 0.04)$ to WT DNA background by using wild type NRAS c.38G>A (G13D) probe.

\section{Comparison between PNA-clamp QUASAqPCR and ASLNA-qPCR on cell line control}

Analytical sensitivity of ASLNA-qPCR was performed by Bizhar Tayeb (previous MSc student). DNA from $B R A F^{\mathrm{V} 600 \mathrm{E}}$ mutated A375-P cell line was serially diluted into WT DNA from HCT-116 cell line. It was found that samples with higher concentration of mutant DNA were amplified at lower $\mathrm{Ct}$ than samples with lower concentration of mutant DNA. The ratios of mutant the NRAS c.38G>A (G13D) DNA for each dilution was as the following: 0.5, 0.25, 0.125, $0.06,0.03,0.015,0.008,0.004,0.002,0.001$, $0.005,0.0002$ and 0.0001 . The ratio of mutant DNA to WT background, that was detectable, was
$1.1000 \quad(\mathrm{P}<0.01)$ (figure 8). However, in this study, the analytical sensitivity of PNA-clamp QUASAqPCR was carried out and the ratios of mutant DNA for each dilution were $0.25,0.125$, $0.0625,0.0312,0.0156,0.0078,0.0039,0.002$, 0.001 and 0.0005 . The results show that PNAclamp QUASAqPCR could significantly detect less than 1:2000 $(\mathrm{P}<0.01)$ indicating that this assay is more sensitive than ASLNA-qPCR technique as it detected an exceptionally low amount of mutant DNA within high WT background and the efficiency of the assay was very high $98.8 \%$ (figure 9.). As it is clear from the figure 3.10 the linear correlation between both mutant DNA concentrations and $\mathrm{Ct}$ values is significantly negative. 


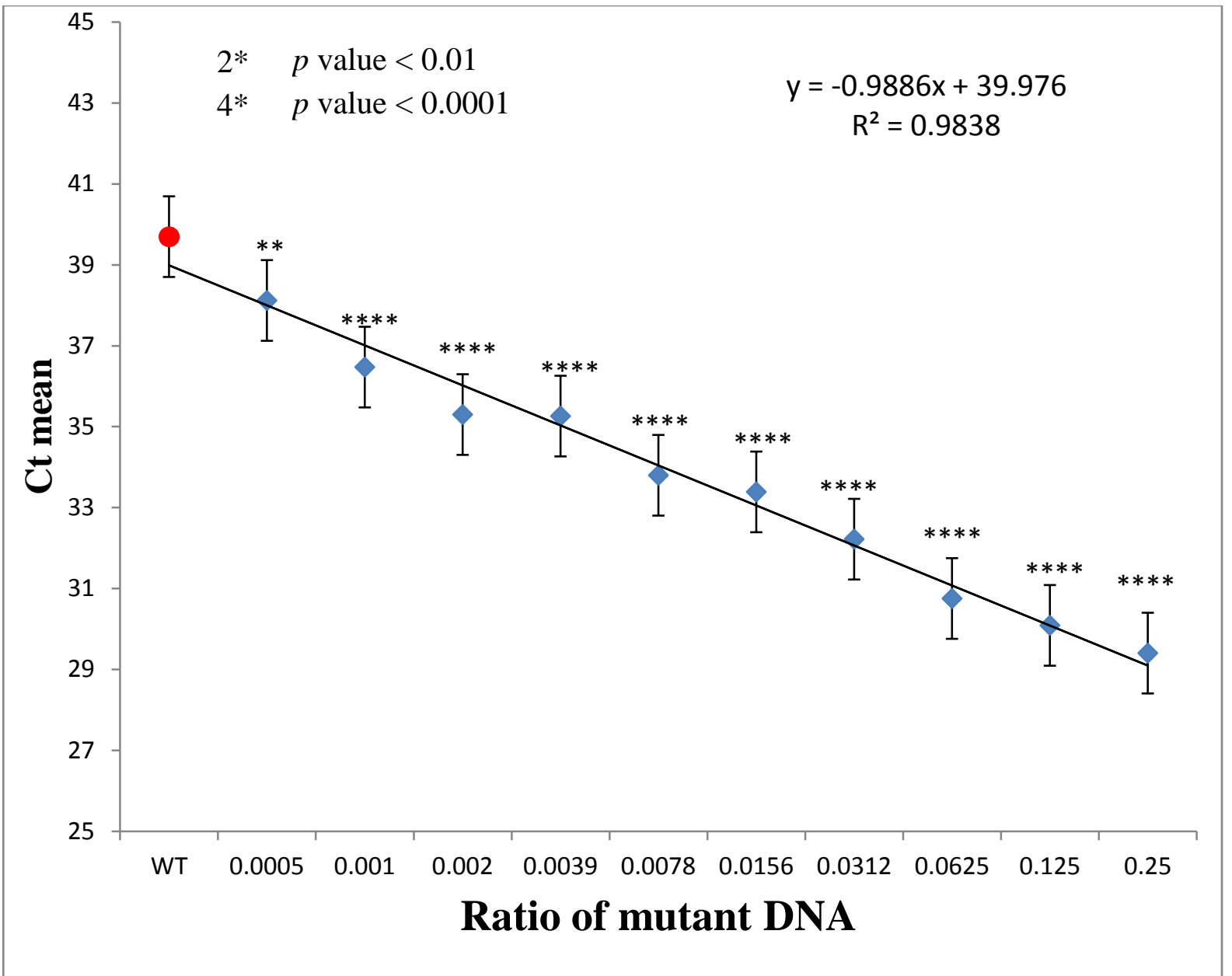

Fig. (8): Standard curve titration of the PNA-clamp QUASAqPCR for NRAS c.38G>A (G13D). Serial dilution of the $N R A S$ c.38G>A (G13D) mutated NCI-H929 cell line DNA in WT DNA. Blue squares correspond to 0.25, 0.125, $0.0625,0.0312,0.0156,0.0078,0.0039,0.002,0.001$ and 0.0005 of mutant to WT ratios (triplicate samples). Efficiency of the assay $=98.8 \%$. The red circle $=$ WT reference DNA. $*=$ represents that there is statistically significant difference between the values and the WT (control) by using the Tukey's multiple comparisons test in ANOVA. 


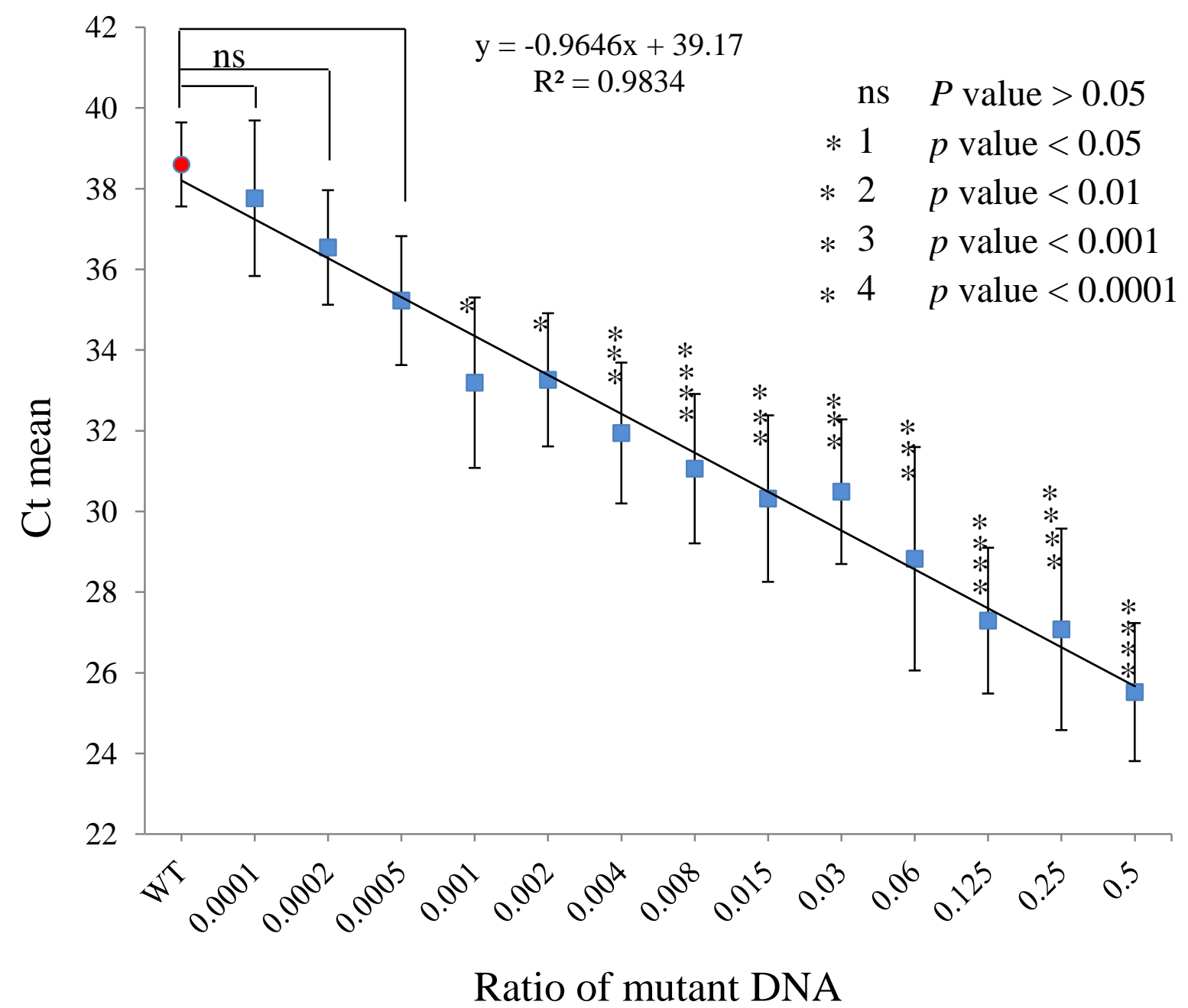

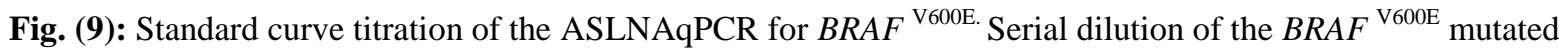
A375-P cell line DNA in WT DNA. Red Squares represents to 0.5, 0.25, 0.125, 0.06, 0.03, 0.015, 0.008, 0.004, $0.002,0.001,0.0005,0.0002,0.0001$ of mutant to WT ratios. The red circle $=$ WT reference DNA. $*=$ there is statistically significant difference between the values and the WT (control) by using the Tukey's multiple comparisons test in ANOVA. (From previous year MSc student).

\section{ASLNAqPCR on clinical samples to detect $B R A F$ V600E}

A total of 84 retrospective tissues were obtained from Leicester Royal Infirmary (LRI) and tested for $B R A F^{\mathrm{V} 600 \mathrm{E}}$ mutation. Samples were separated based on the location of the lesion of the colon in to left and right sided tissues. The tissues obtained from rectum, sigmoid, and the distal third of the transverse colon represent left sided tissues. However, the tissues obtained from proximal two thirds of the transverse colon, ascending colon and caecum represent the right sided tissues. A total of $11.90 \%$ of samples were from right adenomatous lesions, $28.57 \%$ from left adenomatous lesions, $22.61 \%$ from left carcinoma, $27.38 \%$ from right carcinoma, $4.76 \%$ from right sided hyperplastic polys and $4.76 \%$ from left sided hyperplastic polyps. In terms of age, $55.57 \%$ of them were older than 70 years, $29.57 \%$ were between 60-70 years old and $16.66 \%$ were between 50-60 years old. DNA was extracted from all samples and it was quantified using the Nanodrop spectrphotometer (ND-100 Technologies, V3.2.1, USA). ASLNAqPCR assay is based on allele specific PCR and is ideally suited to detect point mutations in BRAF V600E gene. The LNA wild-type specific primer and LNA mutation specific primer for BRAF $\mathrm{V} 600 \mathrm{E}$ were desigend to amplify the wild type and mutant alleles, respictively. PNA was used with the LNA mutation specific primer in order to block the amplification of the WT alleles and allow the 
amplification of the mutant alleles. However, the PNA was not added to the reactions that contain LNA wild-type specific primer. SK-MEL 28 and SK-MEL5 cells which are known to harbour the BRAF ${ }^{\mathrm{V} 600 \mathrm{E}}$ mutations were used as positive controls. Both SK-MEL- 28 and SK-MEL-5 cells are human melanoma cell lines. However, the SKMEL- 28 is homozygous for $B R A F$ c.1799T >A (V600E), but and SK-MEL-5 is heterozygous. Furthermore, the HGDNA was also used as a positive control. As it was expected, the results showed that PNA suppressed the amplification of the WT DNA and allowed the amplification of MUT DNA. With PNA the HGDNA was not quantified but the DNA that was extracted from the cell lines was quantified (SK-MEL $28 \mathrm{Ct}$ mean $=28.42$ and the SK-MEL-5 Ct mean= 32.32). On the other hand, without PNA the HGDNA was quantified at the low $\mathrm{Ct}$ which was 27.98. Therefore, the samples that amplified with the presence of PNA were expected to be positive to the $B R A \mathrm{~F}^{\mathrm{V} 600 \mathrm{E}}$ mutation (figure 10).

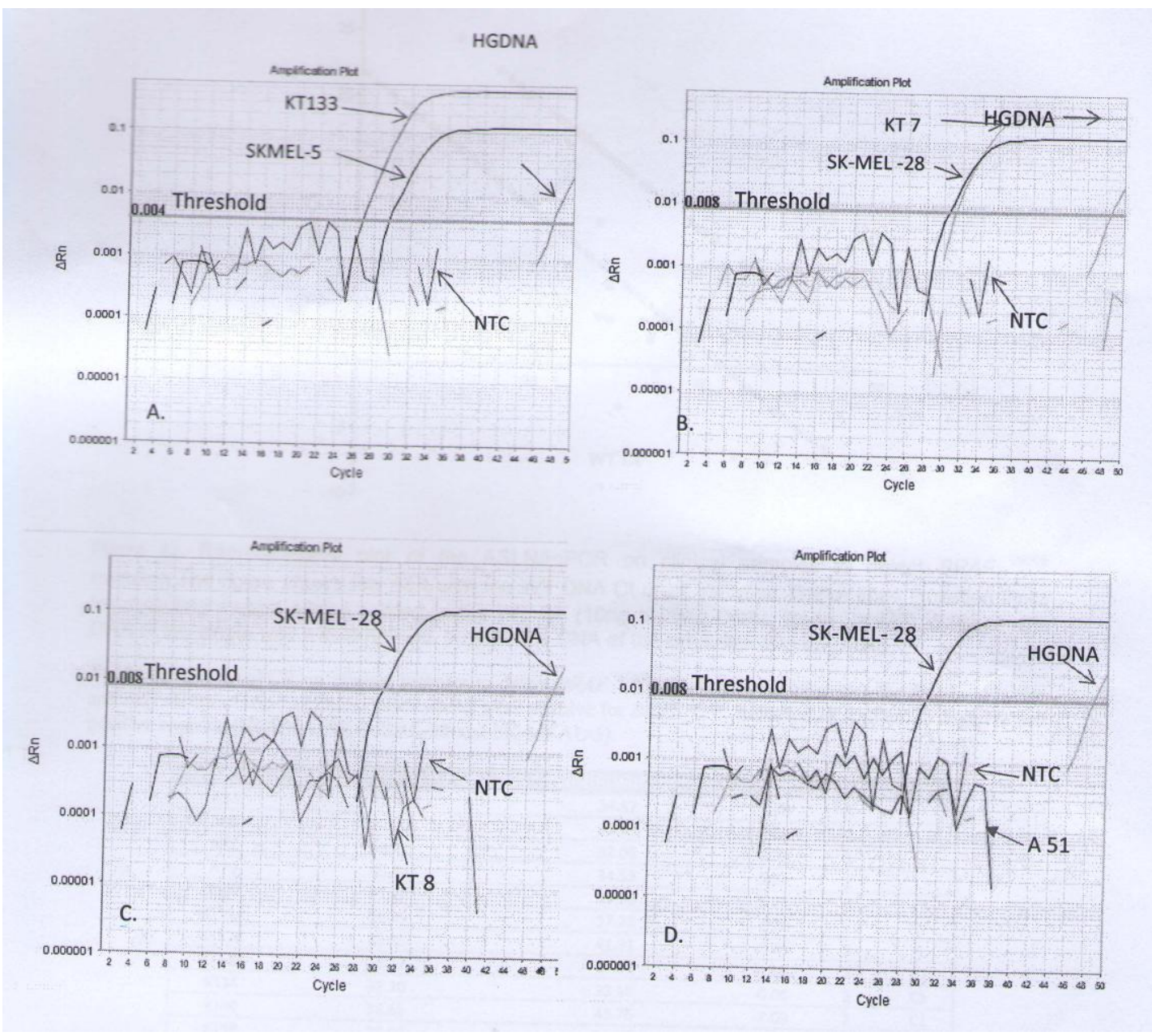

Figure 10. PNA- clamp PCR. Amplification plots of $B R A F^{\mathrm{V} 600 \mathrm{E}}$ florescence versus cycle number show the specificity of PNA-clamp PCR. A. The figure shows that the PNA suppressed the amplification of WT-DNA (HGDNA) and only the MUT-DNA (K133 and SK-MEAL-5) was amplified. B. The figure shows that the PNA suppressed the amplification of WT-DNA (HGDNA) and only the MUT-DNAs (K7 and SK-MEAL-28) were amplified. C and D. The figures show that the cell line (SK-MEL-28) was amplified but HGDNA, KT 8 and A51 were suppressed by PNA. HGDNA= Human genomic DNA, SK-MEL-5= heterozygous cell line, SK-MEL-28= Homozygous cell line, KT133, KT 7 and KT 8= left carcinoma, A $51=$ left adenoma, and NTC= non template control. 


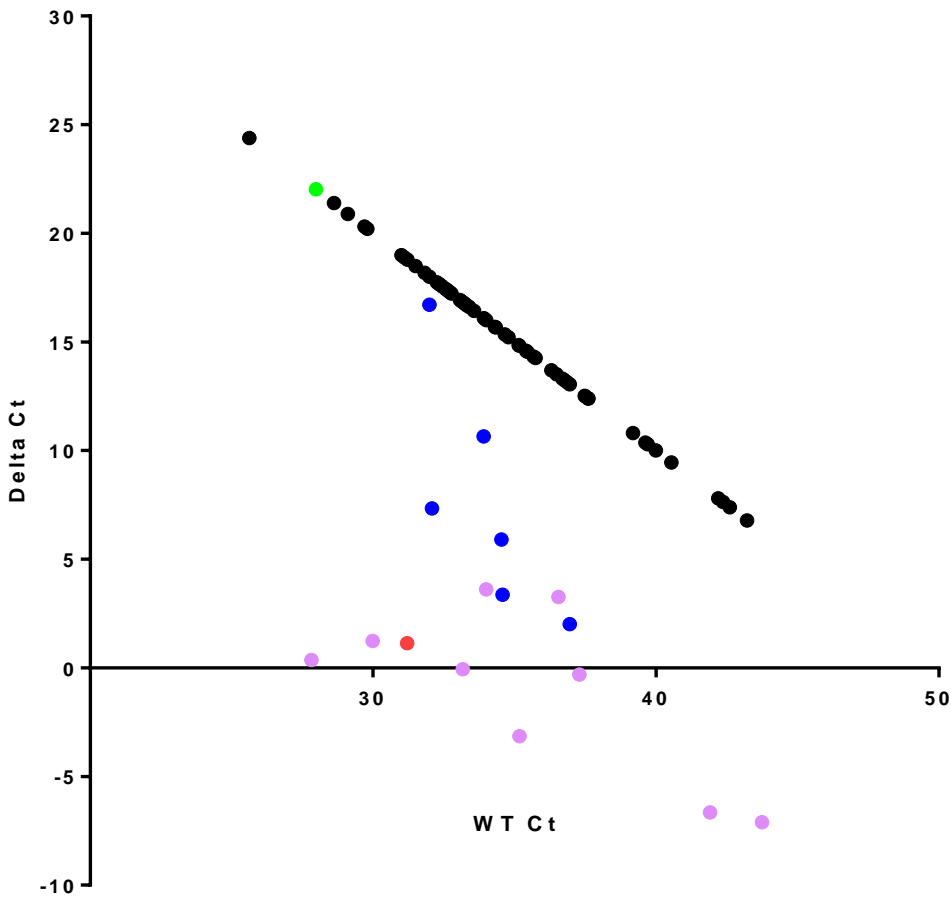

Fig. (11): Representative plot of the ASLNAqPCR on clinical samples to detect $B R A F^{\mathrm{V} 600 \mathrm{E}}$ mutation. The figure shows the $\triangle \mathrm{Ct}$ with the WT DNA Ct of all samples. Green line= limitation limits for detecting mutant alleles related to the WT CT (10ng starting DNA), Red=SK-MEL 5, Blue= the DNA of the single well was amplified, purple $=$ the DNA of the two wells was amplified.

Table (9): ASLNAqPCR on clinical samples to detect $B R A F^{\mathrm{V} 600 \mathrm{E}}$.The table demonstrates the threshold cycles and $\triangle \mathrm{Ct}$ values of the 13 clinical cases which were positive for $B R A F^{\mathrm{V} 600 \mathrm{E}}$ mutation as well as the negative and positive controls (HGDNA, SK-MEAL-28 and SK-MEAL-5).

\begin{tabular}{cccccc}
\hline Samples & MUT Ct mean with PNA & WT Ct mean without PNA & $\Delta$ Ct & status & Stage \\
\hline A22 & 37.93 & 34.57 & 3.36 & 1 & \\
\hline A55 & 37.60 & 33.99 & 3.60 & 2 & \\
\hline A52 & 39.41 & 32.08 & 7.33 & 1 & \\
\hline A79 & 40.44 & 34.53 & 5.91 & 1 & \\
\hline KT07 & 31.22 & 29.98 & 1.23 & 2 & C1 \\
\hline KT114 & 36.99 & 37.29 & -0.30 & 2 & B \\
\hline KT124 & 35.25 & 41.91 & -6.65 & 2 & $\mathrm{C}$ \\
\hline KT133 & 28.17 & 27.81 & 0.35 & 2 & $\mathrm{C} 1$ \\
\hline KT14 & 33.10 & 33.16 & -0.06 & 2 & $\mathrm{C} 1$ \\
\hline KT30 & 36.65 & 43.75 & -7.09 & 2 & $\mathrm{C1}$ \\
\hline KT58 & 32.02 & 35.17 & -3.14 & 2 & $\mathrm{~B}$ \\
\hline KT80 & 39.81 & 36.55 & 3.25 & 2 & $\mathrm{C}$ \\
\hline HP64 & 38.96 & 36.95 & 2.01 & 1 & \\
\hline HGDNA & $<50$ & 27.98 & 22.02 & & \\
\hline SK-MEL 5 & 32.328 & 31.19 & 1.12 & 2 & \\
\hline SK-MEL & 28.42 & 49.71 & -21.29 & 2 & \\
28 & & & & & \\
\hline
\end{tabular}

$\mathrm{WT}=$ wild type primer; $\mathrm{MUT}=$ mutation specific primer; $\mathrm{Ct}=$ cycle threshold; $\Delta \mathrm{Ct}=$ delta $\mathrm{Ct} ; \mathrm{A}=$ adenomatous; $\mathrm{HP}=$ hyperplastic polys; KT= carcinoma; HGDNA= human genomic DNA; SK-MEAL-28= homozygous human melanoma cell line; SK-MEL 5= heterozygous human melanoma cell line, $(\mathrm{M})=$ moderate, $(\mathrm{P})=$ poor, $1=\mathrm{DNA}$ was amplified only in a single well and $2=$ DNA amplified in double wells. 
The Ct mean of the WT allele specific primers for each sample was taken and plotted with their $\Delta \mathrm{Ct}$. A line was drawn after ten cycles of the amplification of cell line and considered as theoretical limits for detecting mutant alleles related to the WT Ct (10ng starting DNA) (figure 11). Of all cases investigated, $15.47 \%$ (13/84) showed mutation in BRAF V600E. (table 9). Chi square and Fisher's Exact tests were used to show the effect of age, gender and tumour location on mutations in $B R A F^{\mathrm{V} 600 \mathrm{E}}$. Among the $B R A F^{\mathrm{V} 600 \mathrm{E}}$ positive samples, $69.23 \%$ of cases were older than 70 years, $15.38 \%$ cases were between $60-70$ years old and $15.38 \%$ patients were between 50 60 years old. Moreover, among the 8 carcinoma positive samples, six of them were at stage $\mathrm{C}$ and the others were at stage B (Table 10). It was observed that there is no statistically significant association between age and mutations in $B R A F$ ${ }^{\mathrm{V} 600 \mathrm{E}}(\mathrm{P}<0.40)$. However, it was found that there is statisticaly siginificant relationship between tumor location and $B R A F$ V600E mutaions $(\mathrm{P}<$ 0.014) (figure 11). Amongst the positive $B R A F$ $\mathrm{V} 600 \mathrm{E}, 76.92 \%$ cases were right sided, while only $23.07 \%$ were left sided. In terms of gender, as it is clear from the table 3.6, there is no significant association between type of gender and $B R A F$ V600E mutaions $(\mathrm{P}<0.83) \quad($ table 10$)$.

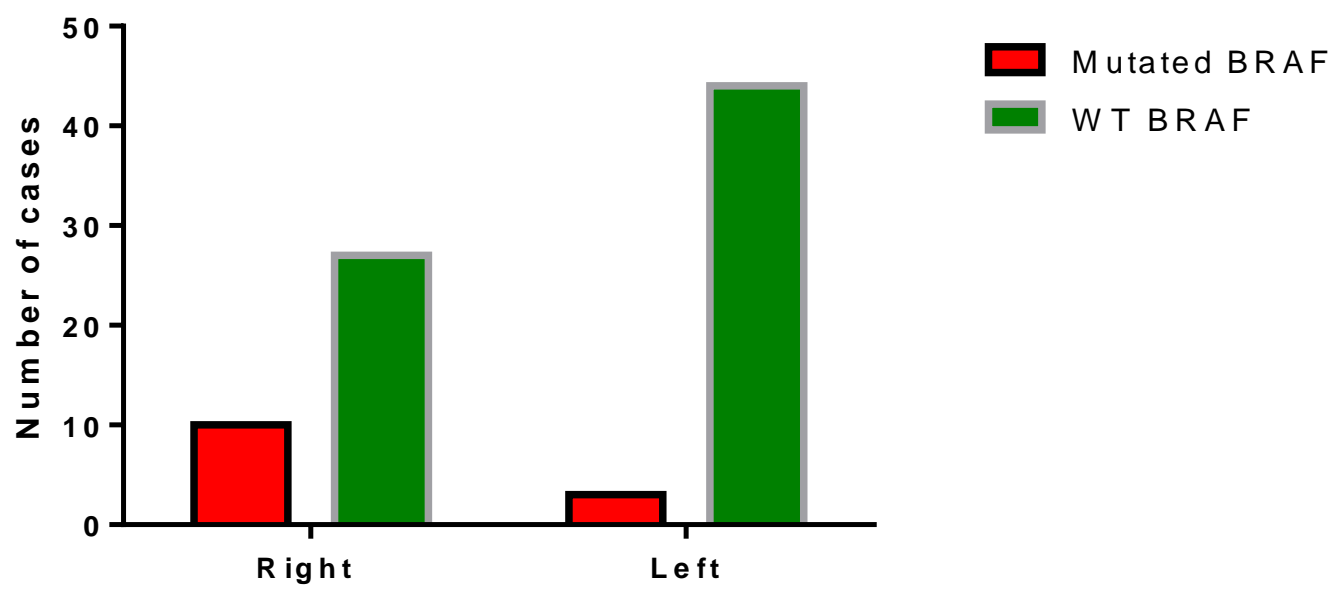

Fig. (11): The relationship between $B R A F^{\mathrm{V} 600 \mathrm{E}}$ mutations and tumor location. The figure shows that there is significant association between right side tumor and $B R A F^{\mathrm{V} 600 \mathrm{E}}$ mutation $(\mathrm{P}<0.014)$. 
Table (10): Clinicopathological and molecular features of 84 analysed tumour cases. The table shows the frequency and incidence of $B R A F^{\mathrm{V} 600 \mathrm{E}}$ muattion and its association with age, gender and tumour location.

\begin{tabular}{|c|c|c|c|}
\hline Feature & Total (\%) & No. of BRAF mutation & P-value \\
\hline \multicolumn{4}{|c|}{ Age } \\
\hline \multirow[t]{2}{*}{$50-60$} & $14(16.66)$ & $2(15.38)$ & \\
\hline & & & 0.40 \\
\hline $60-70$ & $25(29.76)$ & $2(15.38)$ & \\
\hline \multirow[t]{2}{*}{$<70$} & $45(53.57)$ & $9(69.23)$ & \\
\hline & \multicolumn{2}{|c|}{ Gender } & \\
\hline \multirow[t]{2}{*}{ Male } & $43(51.19)$ & $7(53.84)$ & \\
\hline & & & 0.83 \\
\hline \multirow[t]{2}{*}{ Female } & $41(48.80)$ & $6(46.15)$ & \\
\hline & \multicolumn{2}{|c|}{ Tumour location } & \\
\hline \multirow[t]{2}{*}{ Right-sided } & $37(44.04)$ & $10(76.92)$ & \\
\hline & & & 0.014 \\
\hline Left- sided & $47(55.95)$ & $3(23.07)$ & \\
\hline
\end{tabular}

\section{PNA-clamp PCR on clinical sample to detect NRAS gene mutations}

Detection of NRAS gene mutations by using allele specific probes

The same samples that were tested for $B R A F$ ${ }^{\mathrm{V} 600 \mathrm{E}}$ mutation were also tested for NRAS codons 12 and 13 mutations. NRAS c.34G>T (G12C), $N R A S \quad$ c.35G>A (G12D) and $N R A S \quad$ c. $38 \mathrm{G}>\mathrm{A}$ (G13D) are considered as the most frequent mutations in NRAS gene. Therefore, the probes were designed to detect these three mutations. However, another allele specific probe was designed to amplify WT DNA. MOLT-4, THP-1 and NCI-H929 cell lines were used as positive controls for NRAS c.34G>T (G12C), NRAS c.35G>A (G12D) and NRAS c.38G>A (G13D), respectively. Moreover, HGDNA was used as positive control for WT DNA and sterile UP water was used as non- template control. PNA probe was used with the mutant allele specific probe to block the amplification of the WT DNA and allow the amplification of the mutant DNA. On the other hand, it was not used with the WT allele specific probe reactions. It was found that the HGNDA with PNA was quantified at high Ct (44.48), but it was quantified at vey lower $\mathrm{Ct}$ (26.13) without PNA. The DNA that was extracted from three heterozygous cell lines was amplified with both mutant and WT allele specific probes. Moreover, there were no PCR products with negative control. Amongst 84 samples, only one sample was seemed to be positive for NRAS c.38G >A (G13D) mutation, but it was on the border line of detection. In terms of NRAS c.35G>A (G12D) mutation, the figure 12 and 13 and table 11 Show that 2 samples are seem to be positive. However, one of them was in the border line of detection. Finally, none of the samples was found to be mutated with NRAS c.34G>T (G12C). Overall, it was observed that the probes were not specific enough and not well optimized for detection of mutations because there were a lot of background and many samples were amplified only in one well with the mutant specific probes (figure 12). 

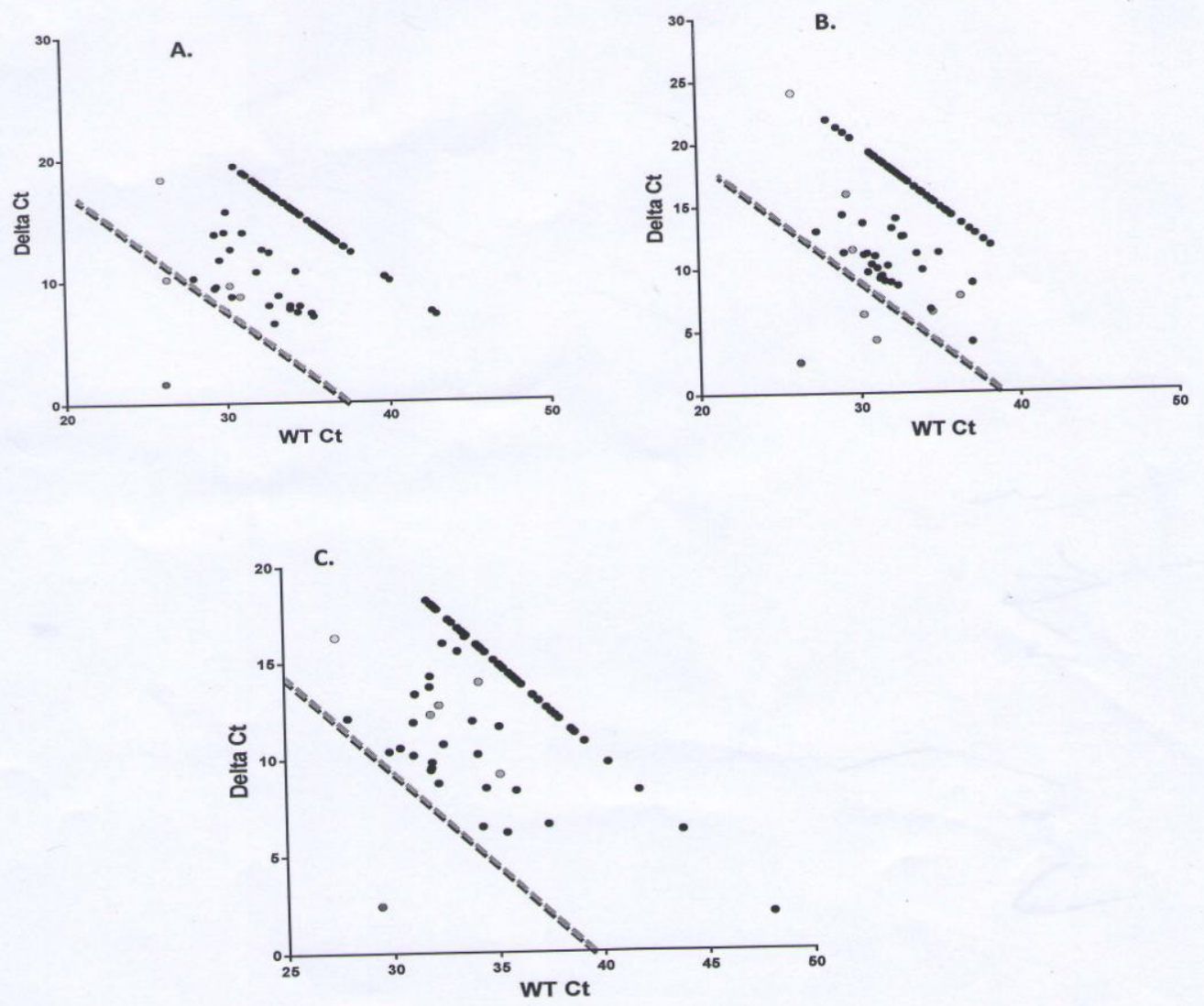

Fig. (12): Representative plots of the PNA-clamp PCR on clinical samples to detect NRAS gene mutation. A. The figure shows the $\Delta \mathrm{Ct}$ and the WT probe $\mathrm{Ct}$ of all samples for $N R A S$ c.38G $>\mathrm{A}(\mathrm{G} 13 \mathrm{D})$ mutation. B. The figure demonstarets the $\triangle \mathrm{Ct}$ and the WT DNA Ct of all samples for $N R A S$ c.35G $>\mathrm{A}(\mathrm{G} 12 \mathrm{D})$ mutation. C. The figure shows the $\Delta \mathrm{Ct}$ and the WT DNA Ct of all samples for $N R A S$ c.34G $>\mathrm{T}(\mathrm{G} 12 \mathrm{C})$. Line $=10$ cycle after amplification of positive control (cell lines), Green line = limitation limits for detecting mutant alleles related to the WT CT (10ng starting DNA), Red A= NCI-H929, B= THP-1 and $\mathbf{C}=$ MOLT-4 cell line, Blue= the DNA of the single well was amplified, purple $=$ the DNA of the two wells was amplified. 


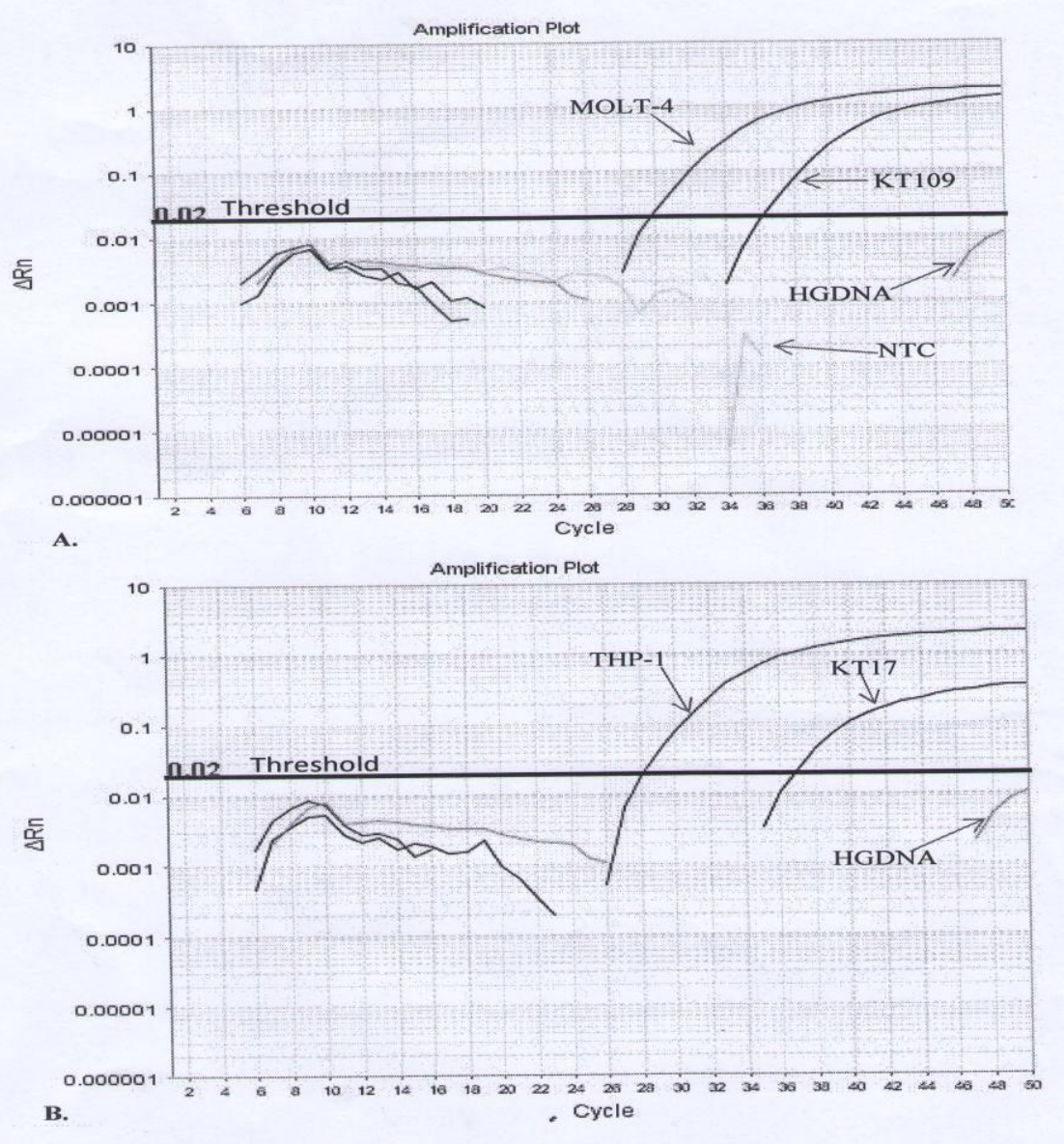

Fig. (13): PNA- clamp PCR. Amplification plots of NRAS codon 12 and 13 florescence versus cycle number show the specificity of PNA-clamp PCR on clinical samples. A. The figure shows the amplification of mutant NRAS

c.34G>T (G12C) probe with MOLT-4 cell line, HP237 sample and HGDNA. B. the figure demonstrates the amplification of mutant NRAS c.35G>A (G12D) probe with THP-1 cell line, KT17 sample and HGNDA.

HGDNA= Human genomic DNA, KT17= carcinoma, HP237= hyperplastic polyps and NTC $=$ non template control.

Table 11. PNA- clamp PCR on clinical samples to NRAS codons 12 and 13 mutations. The table demonstrates the threshold cycles and $\triangle \mathrm{Ct}$ values of the three clinical cases which were positive for NRAS mutation.

\begin{tabular}{cccccc}
\hline Samples & Probe & MUT Ct mean with & WT Ct mean without & PCt & status \\
& & PNA & PNA & & \\
\hline HP237 & NRAS c.38G $>$ A (G13D) & 36.54 & 26.39 & 10.14 & 1 \\
\hline KT17 (A) & NRAS c.35G $>$ A (G12D) & 42.17 & 32.91 & 9.261 & 1 \\
\hline KT109 (B) & NRAS c.35G $>$ A (G12D) & 45.05 & 34.33 & 10.71 & 1 \\
\hline
\end{tabular}

$\mathrm{WT}=$ wild type allele specific probe; $\mathrm{MUT}=$ mutation allele specific probe; $\mathrm{Ct}=$ cycle threshold; $\Delta \mathrm{Ct}=\mathrm{delta} \mathrm{Ct} ; \mathrm{HP}=$ hyperplastic polys; KT= carcinoma; 1= DNA was amplified only in a single well,(A) and (B)= stage of CRC.

\section{Detection of NRAS gene mutations by using allele specific primers}

As results obtained from using allele specific probes were not convincing. Therefore, the samples had to be analysed by allele specific primers as well. The samples, that were positive or were between positive and negative line, were selected to be re-analysed with allele specific 
primers. The same positive and negative controls that used with allele specific probes were used with allele specific primers as well. Four samples (HP237, KT103, A39 and A180) were found to be positive for NRAS c.38G>A (G13D) mutation. However, only in two of them the DNA was amplified in both wells. In terms of NRAS c.35G>A (G12D) mutation, two samples (KT17 and KT109) were seen to be positive (Figure 14 and 15). Finally, as it is clear from figure 14 three samples are seems to be positive for NRAS c.34G>T (G12C) mutation. Nevertheless, one of them was in the border line of detection and it was not positive with probes (Figure 14 and 15). Thereby, it was considered as WT for NRAS c.34G>T (G12C) mutation. All the samples that were positive with allele specific probes were also positive with allele specific primers. However, there were another six positive samples with only allele specific primers (table 12). One of the cases (HP237) was positive for both NRAS c.34G>T (G12C) and NRAS c.38G>A (G13D) mutations.
After samples had been tested with allele specific primers and allele specific probes, NRAS mutation was observed in $8.33 \%$ cases. Chi square and Fisher's Exact tests were used to know the effect of age, gender and tumour location on mutations in NRAS codon 12 and 13. It was found that there is no statistically significant association between age and mutations NRAS codons 12 and 13 ( $\mathrm{P}<0.98$ ) (table 13). Among NRAS positive samples, $14.28 \%$ of them were between 5.-60 years old, $28.57 \%$ were between $60-70$ and 57.14 were older than 70 years older. Moreover, it was also observed that tumoure location and gender do not have staitically significant relation with NRAS mutation ( $\mathrm{P}>1.0)$. 57.14\% of mutated samples were males and $42.85 \%$ of them were females. In terms of tumour location, $57.14 \%$ mutated cases were right sided and $42.57 \%$ left sided (table 13). Furthermore, $14.28 \%$ of mutated samples were from hyperplastic polyps patients, $28.57 \%$ of them were from adenomatous and $57.14 \%$ were from carcinoma pationts. Interesingly, the carcinoma positive cases were at stage $\mathrm{A}$ and $\mathrm{B}$.

Table 12. PNA- clamp PCR on clinical samples to NRAS codons 12 and 13 mutations. The table demonstrates the threshold cycles and $\triangle \mathrm{Ct}$ values of the seven clinical cases which were positive for NRAS mutation.

\begin{tabular}{clccccc}
\hline Samples & \multicolumn{1}{c}{ primer } & $\begin{array}{c}\text { MUT Ct mean } \\
\text { with PNA }\end{array}$ & WT Ct mean without PNA & $\Delta$ Ct & status & Stage \\
\hline HP237 & NRAS c.38G>A (G13D) & 35.00 & 27.25 & 7.75 & 2 \\
\hline KT103 & NRAS c.38G>A (G13D) & 38.16 & 29.79 & 8.36 & 2 & $\mathrm{~A}$ \\
\hline A39 & NRAS c.38G>A (G13D) & 36.84 & 27.55 & 9.29 & 1 & \\
\hline A180 & NRAS c.38G>A (G13D) & 34.33 & 25.86 & 8.47 & 1 & \\
\hline KT17 & NRAS c.35G>A (G12D) & 31.74 & 26.71 & 5.02 & 2 & $\mathrm{~A}$ \\
\hline KT109 & NRAS c.35G>A (G12D) & 36.25 & 33.12 & 3.13 & 2 & $\mathrm{~B}$ \\
\hline HP237 & NRAS c.34G>T (G12C) & 35.51 & 27.25 & 8.26 & 2 & \\
\hline KT12 & NRAS c.34G>T (G12C) & 34.21 & 25.27 & 8.93 & 2 & $\mathrm{~B}$ \\
\hline
\end{tabular}

$\mathrm{WT}=$ wild type primer; $\mathrm{MUT}=$ mutation specific primer; $\mathrm{Ct}=$ cycle threshold; $\Delta \mathrm{Ct}=$ delta $\mathrm{Ct} ; \mathrm{A}=$ adenomatous; $\mathrm{HP}=$ hyperplastic polys; KT= carcinoma; HGDNA= human genomic DNA; 1= DNA was amplified only in a single well, $2=$ DNA amplified in double wells. 


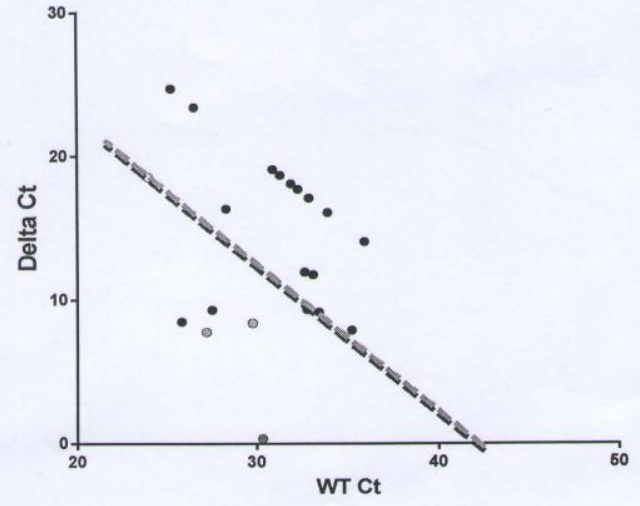

A.

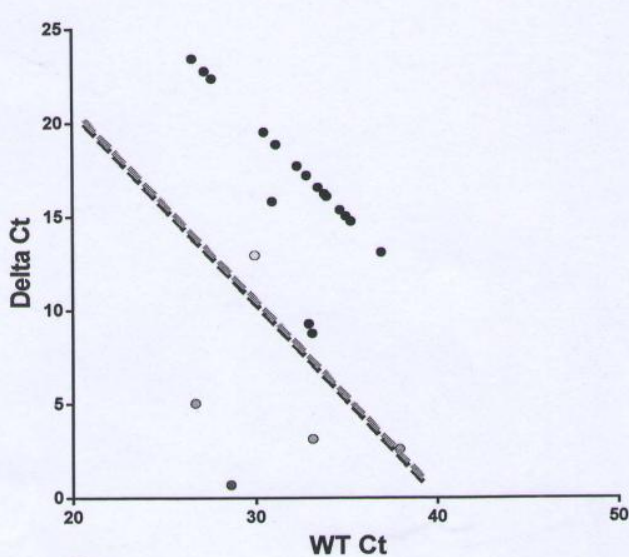

B.

C.

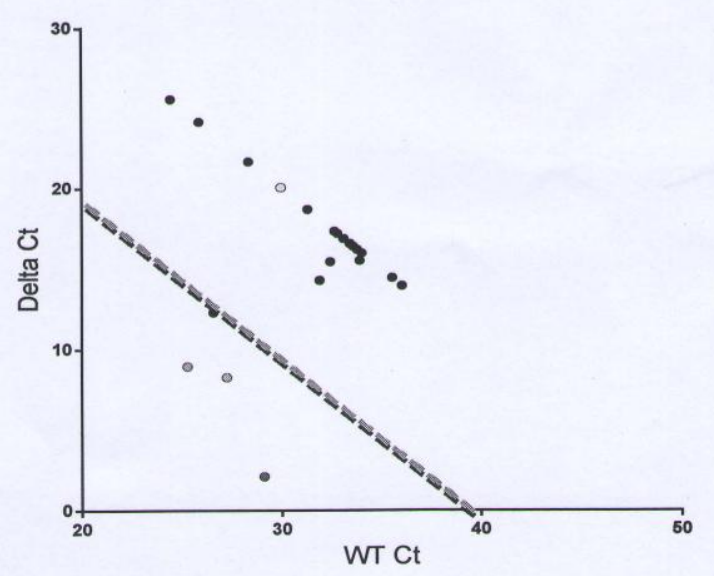

Fig. (14): Representative plots of the PNA-clamp PCK on clinical samples to detect NRAS' gene mutation. A. 'I'he figure shows the delta $\mathrm{Ct}$ and the WT DNA Ct of all samples for $N R A S$ c.38G $>\mathrm{A}(\mathrm{G} 13 \mathrm{D})$ primer. B. The figure demonstarets the delta $\mathrm{Ct}$ and the WT DNA Ct of all samples for NRAS c.35G>A (G12D) primer. C. The figure shows the delta $\mathrm{Ct}$ and the WT DNA Ct of all samples for NRAS c.34G $>\mathrm{T}(\mathrm{G} 12 \mathrm{C})$ primer. Green line $=$ theoritical limits for detecting mutant alleles related to the WT Ct (10ng starting DNA), Red A= NCI-H929, B= THP-1 and C= MOLT -4 cell line, Blue $=$ the DNA of the single well was amplified, purple $=$ the DNA of the two wells was amplified. 

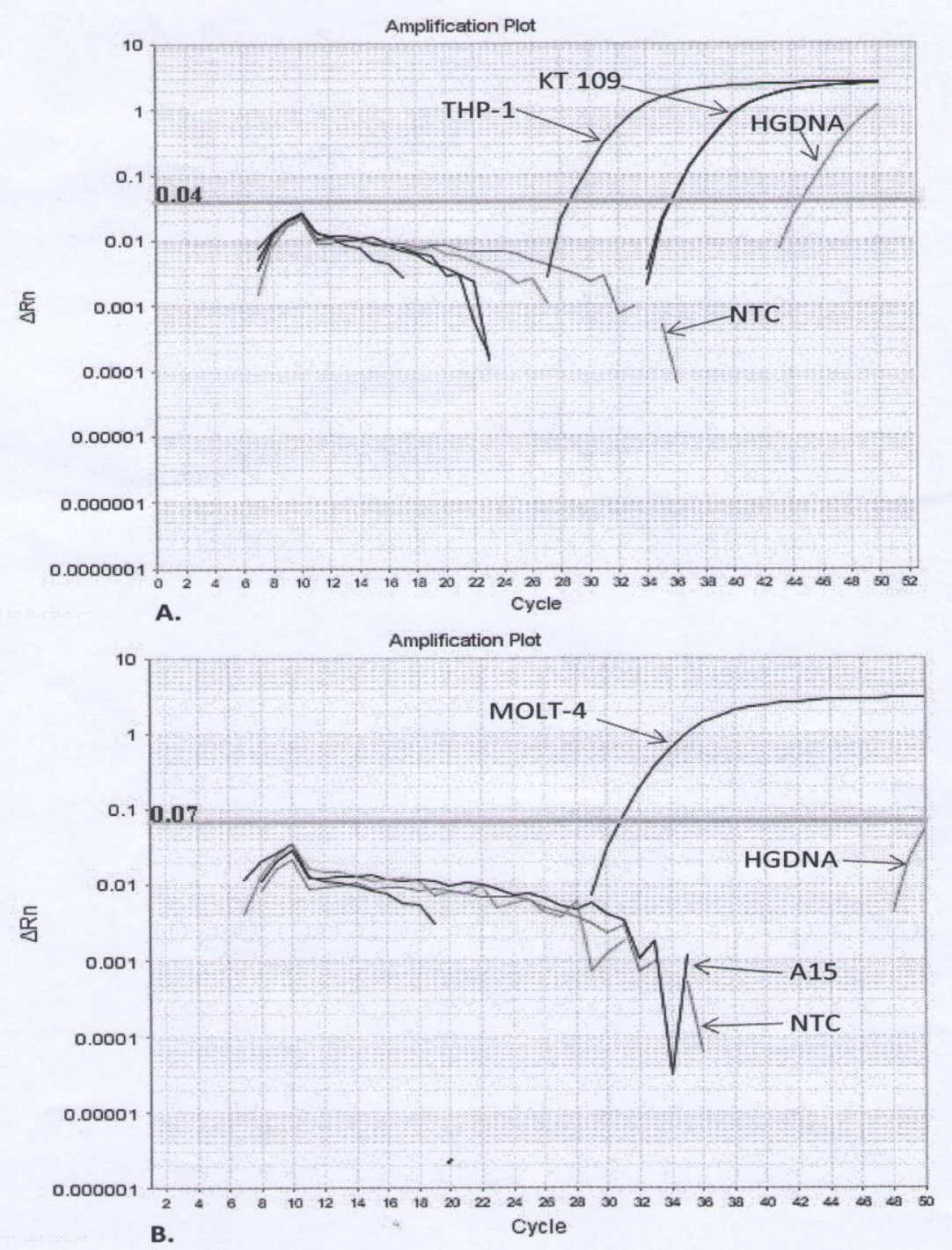

Fig. (15): PNA- clamp PCR. Amplification plots of $N R A S$ codon 12 and 13 florescence versus cycle number show the specificity of PNA-clamp PCR on clinical samples. A. The figure shows the amplification of mutant NRAS c.35G>A (G12D) primer with THP-1 cell line, KT109 sample and HGDNA. B. the figure demonstrates the amplification of NRAS c.34G $>\mathrm{T}$ (G12C) primer with MOLT-4 cell line, A15 sample and HGDNA. HGDNA= Human genomic DNA, KT109= carcinoma, A15= adenoma and NTC= non template control. 
Table 13. Clinicopathological and molecular features of 84 studied CRC samples. The table shows the frequency and incidence of NRAS codons 12 and 13 muattions and their association with age, gender and tumour location.

\begin{tabular}{|c|c|c|c|}
\hline Feature & Total (\%) & No. of NRAS mutation & P-value \\
\hline \multicolumn{4}{|l|}{ Age } \\
\hline \multirow[t]{2}{*}{$50-60$} & $14(16.66)$ & $1(14.28)$ & \multirow{4}{*}{0.98} \\
\hline & & & \\
\hline $60-70$ & $25(29.76)$ & $2(28.57)$ & \\
\hline$<70$ & $45(53.57)$ & $4(57.14)$ & \\
\hline \multicolumn{4}{|l|}{ Gender } \\
\hline \multirow[t]{2}{*}{ Male } & 43 (51.19) & $4(57.14)$ & \multirow{3}{*}{1.00} \\
\hline & & & \\
\hline Female & $41(48.80)$ & $3(42.85)$ & \\
\hline
\end{tabular}

Tumour location

\begin{tabular}{lccc}
\hline Right-sided & $37(44.04)$ & $4(57.14)$ & 1.00 \\
\hline Left- sided & $47(55.95)$ & $3(42.57)$ & \\
\hline
\end{tabular}

\section{DISCUSSION}

Worldwide, it is reported that more than 608,000 deaths and 1.2 million cases are attributed to this cancer (Countinho et al, 2013). There is evidence that an accumulation of genetic changes lead to the progression of CRC from normal tissue to carcinoma. The data suggests that $A P C, K R A S$, $B R A F$ and NRAS are the most widely affected genes (Vaughan et al, 2011). Allele- specific PCR is reported to be one of the most widely used methods for detecting mutations in $B R A F$ V600E and NRAS. Although in this technique the primers are designed to bind at site of mutation, significant mismatched amplification usually occurs (Liu et al, 2012). In this project QUASAqPCR and ASLNAqPCR were used with the Peptide nucleic acid (PNA). PNAs are DNA mimic, in which the negatively charged deoxyribose phosphate backbone is replaced by an uncharged pseudopeptide backbone $\mathrm{N}$-(2-aminoethyl) glycine units linked by peptide bonds (Skronski et al, 2011). The higher stability of a PNA-DNA duplex in comparison to the corresponding DNA-DNA duplex and the higher specificity of PNA binding are the basis for this fundamental technique (Nielsen et al, 2010). This method comprises a distinct annealing phase involving the PNA targeted against one of the primer sites. The formation of a PCR product is effectively blocked by the formation of PNA/DNA complex at one of the primers sites. PNA is also able to distinguish between single mismatch and fully complementary in a mixed target PCR (Ray et al, 
2000). Allele specific PCR (AS-PCR) is commonly used technique for detection of point mutations including $B R A F^{\mathrm{V} 600 \mathrm{E}}$ and $N R A S$ mutations. This technique is based on the principle that extension of primer only occurs when 3'end nucleotide of a primer perfectly matches its target (Morlan et al. 2009). Nevertheless, the occurrence of considerable mismatched amplification is commonly found in practice. Therefore, amplification of WT allele is not eliminated, when the 3 'end nucleotide of allele specific primer anchors at the specific mutant base, but its amplification is reduced (Morlan et al. 2009). Each mutant primer was only amplified with its appropriate cell line apart of 697 cell line. Conversely, it was not quantified with the HGDNA (WT DNA). As it was expected, the WT allele specific primers were amplified with all cell lines and with the HDNA. This is because all the cell lines were heterozygous. Three allele specific probes were also designed in the same way that allele specific primers were designed but with the higher Tm. The specificity and selectivity were found to be slightly higher with allele specific probes than primers on cell lines especially with NRAS c. $34 \mathrm{G}>\mathrm{T}(\mathrm{G} 12 \mathrm{C})$ probe because $\Delta \mathrm{Ct}$ was 2.26 with the NRAS c.34G>T (G12C) primer, but it was 1.80 with NRAS c.34G>T (G12C) probe. This is probably because the assay for the allele specific primers was not well optimized. However, it is worth knowing that in this study, touchdown (TD) PCR method was used with all PNA-clamp QUASAPCR reactions to increase the specificity and sensitivity of binding primers and/ or probes to target sequence and avoid amplifying nonspecific products. This method is utilized to rapidly optimize PCRs without the need for redesigning primers and/or probes, or the length optimizations. TD-PCR employs an initial higher annealing temperature than the estimated melting temperature $\left(T_{\mathrm{m}}\right)$ of the primers. Then, the annealing temperature is progressively decreased (e.g. $1-2^{\circ} \mathrm{C} /$ every second cycle) by using cycling program until it reaches the optimal annealing temperature of the primers (Korbie et al, 2008). 697 cell line is reported to be mutated with NRAS c.34G>T (G12C). However, it was not amplified with its mutant allele specific probes and was amplified at high $\mathrm{Ct}$ with the mutation allele specific primer. Nevertheless, it was amplified with the WT allele specific probe and primer. This indicates that there is no NRAS c.34G>T (G12C) mutation in this version of cell line or probably the wrong cell line was mistakenly labelled. The specificity, selectivity and sensitivity of PNA were validated on three cell lines that were known to harbour appropriate mutations in NRAS codons 12 and 13. The PNA was found to be highly specific as in some cases HGDNA was completely supressed by PNA, but it was quantified at low $\mathrm{Ct}$ without using PNA. On the other hand, the mutant DNA was quantified at low Ct. Moreover, the analytical sensitivity for PNA-clamp QUASAqPCr was performed and it was found that this assay is exceptionally sensitive because even 1:2000 ratio of mutant to WT DNA was significantly detected $(\mathrm{P}<0.01)$.

ASLNAqPCR is a novel allele specific PCR with forward WT and mutant- specific primers modified with locked nucleic acid (LNA) nucleotides at the 3 'end sequence terminal (Morandi et al, 2012). When LNA-modified nucleotides anneal with their DNA complement, an oligonucleotide containing LNAs alter the conformation of this duplex in relative to a normal DNA: DNA duplex and the Tm of DNA heteroduplex considerably increases between 1$8^{\circ} \mathrm{C}$ for each LNA- modified nucleotide (Morandi et al, 2012). LNA oligonucleotides have been used as a blocker to block the WT alleles and increase the sensitivity of PCR. This blocker is reported to be significantly useful to detect mutations in $K R A S, N R A S$ and BRAF (Morandi et al, 2012). The sensitivity of ASLNAqPCR assay was analysed by Bizhar Tayeb and the assay was sensitive enough to statistically detect 1.1000 ratio of mutant DNA into WT DNA background ( $\mathrm{P}<$ 0.01). However, in this project, blocker LNA oligonucleotides were used in combination of clamping PNA to increase the PCR sensitivity for detecting BRAF ${ }^{\mathrm{V} 600 \mathrm{E}}$ mutation. Interpretation of the PNA- clamp ASLNAqPCR technique was depended on the amplification of a PCR product on condition of the presence of respective mutation. The sample was considered as mutant, when amplicon was detected in the mutant allele specific reaction within 10 cycles of the mean $\mathrm{Ct}$ of the WT sequence. Conversely, the sample was considered as negative, if no amplicon was detected. Moreover, reaction were run in duplicate; the mean $\mathrm{Ct}$ values of the WT primer and the $\Delta \mathrm{Ct}$ value $(\Delta \mathrm{Ct}=\mathrm{Ct}$ of mutant primer $-\mathrm{Ct}$ of WT primer) were recorded and were used to define a cut off. If the samples fell under the cut off, they were considered as positive for $B R A F^{\mathrm{V} 600 \mathrm{E}}$ mutation. Adenoma-carcinoma 
sequence has been known as a traditional pathway to CRC and is supported by strong evidence. However, currently, another pathway has been suggested depend on the development of colonic lesions with a serrated morphology. More recently, it is found that the mutation of $B R A F^{\mathrm{V} 600 \mathrm{E}}$ is significantly related to the serrated subtypes hyperplastic polyps (HPs) and adenoma (Kambara et al, 2004). BRAF ${ }^{\mathrm{V} 600 \mathrm{E}}$ is found to be mutated in $10-15 \%$ of CRC in population based studies. This mutation leads to the constitutive activation of the BRAF kinase and induces cell transformation (Ogino et al, 2012). Several studies have shown that mutation in $B R A F^{\mathrm{V} 600 \mathrm{E}}$ is a negative predictor of response from therapy in WT KRAS tumour. Nicolantonio et al (2008) tested 113 CRC patients treated with anti-EGFR therapy, $14 \%$ of them were mutated with $B R A F^{\mathrm{V} 600 \mathrm{E} \text {, }}$ and none of them responded to treatment. On the other hand, all the responders carried WT $B R A F^{\mathrm{V} 600 \mathrm{E}}$. The data suggest that progression free survival and overall survival were considerably shorter in patients with $\mathrm{BRAF}^{\mathrm{V} 600 \mathrm{E}}$ mutation (Nicolantonio et al, 2008). Conversely, Laurent et al (2009) tested 173 previously anti-EGFR treated patients with mCRC and they showed that there is no significantly association between lack of response to anti-EGFR therapy and $B R A F^{\mathrm{V} 600 \mathrm{E}}$ mutations. The BRAF $\mathrm{V} 600 \mathrm{E}$ mutation associations and frequency observed in this project were in concordance and compelling with previous studies. In this project, the $B R A F^{\mathrm{V} 600 \mathrm{E}}$ was found to be mutated in $15.47 \%(13 / 84)$ and its mutation was significantly associated with tumour location $(\mathrm{P}<0.014) .76 .92 \%$ among the positive $B R A F^{\mathrm{V} 600 \mathrm{E}}$ cases were right sided, while only $23.07 \%$ were left sided. This results corespond to Ogino et al (2012) and Roth et al (2010) results as they observed that the muation of $B R A F^{\mathrm{V} 600 \mathrm{E}}$ is highly asssociated with right sided tumour. Conversely, it was found to be non-significantly associated to the gender $(\mathrm{P}<0.83)$ and age $(\mathrm{p}<0.40)$. However, $69.23 \%$ of mutated cases were older than 70 years. Roth et al (2010) observed that $B R A F^{\mathrm{V} 600 \mathrm{E}}$ mutation is highly significantly asscociated with older age $\left(p>10^{-4}\right)$ and with female sex $(P$ $<0.017)$. Moreover, the results show that $19.04 \%$ (8 of 42) of carcinoma, $11.76 \%$ (4 of 34) of adenoma and 12.5( 1 of 8) of HPs had mutation in $B R A F{ }^{\mathrm{V} 600 \mathrm{E}}$. These results do not accordance to Chan et al. results as they found that the frequency of $B R A F^{\mathrm{V} 600 \mathrm{E}}$ mutation is $36 \%$ in HPs (Chan et al, 2003). However, in this study, the number of tested HPs samples was only 8, while they tested 55 samples of HPs. Moreover, Beach et al. report that $B R A F^{\mathrm{V} 600 \mathrm{E}}$ mutation was observed in $75 \%$ of serrated adenoma, $30 \%$ of tubular adenoma, $43 \%$ of HPs , and 33\% of carcinoma (Beach et al, 2005). In this project, among the mutated $B R A F$ V600E carcinoma cases, it was shown that $75 \%$ (6 of 8 ) of them were in stage $\mathrm{C}$ and $25 \%$ (2 of 8 ) were in stage $\mathrm{B}$. The interpretation of the PNAclamp QUASAqPCR assay was done in the same way that PNA- clamp ASLNAqPCR assay was interpreted. Unfortunately, it was observed that the specificity of probes on clinical samples were not as high as on cell lines as there were a lot of background noise. This is an indication of the production of nonspecific sequences because of poor hybridization performance. Probes might miss-anneal to target sequences because of limited amount of target sequences, DNA damaged during formalin fixation process, depurination of the bases, orcontamination from other WT background DNA. However, the samples that were not confirmed whether positive or negative for NRAS mutations were re-analysed by using the allele specific primers. The results of using primers were more convincing than probes as it was clearer to determine which samples are positives. However, although all the reactions were run in duplicate, for some samples the DNA only amplified in one well. Therefore, the specificity was still not as high as it was expected. One reason of occurring this is probably because the number of molecules was not the same in both wells. In other words, one well might contain enough amounts of molecules to be detected, but the other did not. However, only the samples that were positive with mutant primers and probes were declared as positive for NRAS mutation. According to the data from the Sanger Institute COSMIC database (www.sanger.ac.uk/genetics/CGP/cosmic/) the overall incidence of NRAS mutation in CRC cancer is $1-6 \%$. The frequency of $N R A S$ c. $35 \mathrm{G}>\mathrm{A}$ (G12D) mutation was $\sim 17 \%$, NRAS c.34G $>\mathrm{T}$ (G12C) $7.5 \%$, NRAS c.38G> A (G13D) 5.8\%, NRAS c.34G>A (G12S) 5\%, and NRAS c.35G>T $(\mathrm{G} 12 \mathrm{~V}) \sim 4 \%$. However, in this study, among all the analysed samples; NRAS mutation was shown in $8.33 \%$ cases. This mutation has been found to be involved in the primary resistance mechanisms to the anti-EGFR therapy because it is the downstream of the EGFR signalling pathway. Moreover, the median overall survival (OS) in 
mutated $N R A S$ patients were reported to be worse than all WT NRAS indicating that RAS mutation might have a potential negative prognostic role in patient with mCRC (Schirripa et al, 2014). However, while KRAS mutations contribute the transition of intermediate adenoma to carcinoma and are found to be occur in the early phases of carcinogenesis, the NRAS mutations have been observed to be not implicated in the adenomacarcinoma sequence (Schirripa et al, 2014). However, among the NRAS mutated carcinoma cases, $50 \%$ ( 2 of 4 ) of them were in stage A and $50 \%$ were at stage B. Chi square and Fisher's Exact tests were used to show the effect of age, gender and tumour location on mutations in NRAS codons 12 and 13. However, due to the low frequency, its mutation was not significantly related to to any clinacial features (Age $(\mathrm{P}<0.98)$, gender and tumour location $(\mathrm{P}<1.00))$. This observation is consistent with Irahara et al. results because they state that there is no association between the NRAS mutation and any clinicopathological features (Irahara et al, 2010). Although the results do not reach the statistical significant, it was observed that the frequency of NRAS mutation was higher in $<70$ years old patients $(57.14 \%)$ as well as in right sided tumour (57.14). BRAF' KRAS and NRAS mutations are reported to be mutually exclusive and only few studies report concomitant BRAF and NRAS mutations (De et al, 2010). This was confirmed in this study as all of the $B R A F^{\mathrm{V} 600 \mathrm{E}}$ mutated samples were observed to be WT to NRAS and vice versa.

\section{REFERENCES}

- Beach, R., Chan, A. O. O., Wu, T. T., White, J. A., Morris, J. S., Lunagomez, S., ... \& Rashid, A. (2005). < i $>$ BRAF $</$ i $>$ Mutations in Aberrant Crypt Foci and Hyperplastic Polyposis. The American journal of pathology, 166(4), 10691075.

- Brink, M., de Goeij, A. F., Weijenberg, M. P., Roemen, G. M., Lentjes, M. H., Pachen, M. M., ... \& van den Brandt, P. A. (2003). K-ras oncogene mutations in sporadic colorectal cancer in The Netherlands Cohort Study. Carcinogenesis,24(4), 703-710.

- Chan, T. L., Zhao, W., Leung, S. Y., \& Yuen, S. T. (2003). BRAF and KRAS mutations in colorectal hyperplastic polyps and serrated adenomas. Cancer research, 63(16), 4878-4881.

- Coutinho, A. K., Prolla, G., \& Weschenfelder, R. (2013). BRAF, KRAS, and Phosphatidylinositol 3-Kinase in the Management of Metastatic
Colorectal Cancer. Current Colorectal Cancer Reports, 9(1), 57-67.

- De Roock, W., Claes, B., Bernasconi, D., De Schutter, J., Biesmans, B., Fountzilas, G., ... \& Tejpar, S. (2010). Effects of $<\mathrm{i}>\mathrm{KRAS}, \mathrm{BRAF}$, NRAS $</ i>$, and $<\mathrm{i}>$ PIK 3 CA $</ i>$ mutations on the efficacy of cetuximab plus chemotherapy in chemotherapy-refractory metastatic colorectal cancer: a retrospective consortium analysis. The lancet oncology, 11(8), 753-762.

- Dhomen, N. and Marais, R., 2007. New insight into BRAF mutations in cancer. Current opinion in genetics \& development, 17(1), pp.31-39.

- Di Nicolantonio, F., Martini, M., Molinari, F., Sartore-Bianchi, A., Arena, S., Saletti, P., De Dosso, S., Mazzucchelli, L., Frattini, M., Siena, S. and Bardelli, A., 2008. Wild-type BRAF is required for response to panitumumab or cetuximab in metastatic colorectal cancer. Journal of Clinical Oncology, 26(35), pp.5705-5712.

- Douillard, J., Cunningham, D., Roth, A. D., Navarro, M., James, R. D., Karasek, P., ... \& Rougier, P. (2000). Irinotecan combined with fluorouracil compared with fluorouracil alone as first-line treatment for metastatic colorectal cancer: a multicentre randomised trial. The Lancet, 355(9209), 1041-1047.

- Irahara, N., Nosho, K., Baba, Y., Shima, K., Lindeman, N.I., Hazra, A., Schernhammer, E.S., Hunter, D.J., Fuchs, C.S. and Ogino, S., 2010. Precision of pyrosequencing assay to measure LINE-1 methylation in colon cancer, normal colonic mucosa, and peripheral blood cells. The Journal of Molecular Diagnostics, 12(2), pp.177-183.

- Jonker, D. J., O'Callaghan, C. J., Karapetis, C. S., Zalcberg, J. R., Tu, D., Au, H. J., ... \& Moore, M. J. (2007). Cetuximab for the treatment of colorectal cancer. New England Journal of Medicine, 357(20), 2040-2048.

- Kambara, T., Simms, L. A., Whitehall, V. L. J., Spring, K. J., Wynter, C. V. A., Walsh, M. D., ... \& Leggett, B. A. (2004). BRAF mutation is associated with DNA methylation in serrated polyps and cancers of the colorectum. Gut, 53(8), 1137-1144.

- Korbie, D. J., \& Mattick, J. S. (2008). Touchdown PCR for increased specificity and sensitivity in PCR amplification. Nature Protocols, 3(9), 1452-1456.

- Lang, A. H., Drexel, H., Geller-Rhomberg, S., Stark, N., Winder, T., Geiger, K., \& Muendlein, A. (2011). Optimized Allele-Specific Real-Time PCR Assays for the Detection of Common 
Mutations in $<\mathrm{i}>\mathrm{KRAS}</ \mathrm{i}>$ and $<\mathrm{i}>\mathrm{BRAF}</ \mathrm{i}>$. The Journal of Molecular Diagnostics, 13(1), 23-28.

- Laurent-Puig, P., Cayre, A., Manceau, G., Buc, E., Bachet, J.B., Lecomte, T., Rougier, P., Lievre, A., Landi, B., Boige, V. and Ducreux, M., 2009. Analysis of PTEN, BRAF, and EGFR status in determining benefit from cetuximab therapy in wild-type KRAS metastatic colon cancer. Journal of clinical oncology, 27(35), pp.5924-5930.

- Liu, J., Huang, S., Sun, M., Liu, S., Liu, Y., Wang, W., ... \& Hua, W. (2012). An improved allelespecific PCR primer design method for SNP marker analysis and its application. Plant methods, 8(1), 34 .

- Morandi, L., de Biase, D., Visani, M., Cesari, V., De Maglio, G., Pizzolitto, S., ... \& Tallini, G. (2012). Allele specific locked nucleic acid quantitative PCR (ASLNAqPCR): an accurate and cost-effective assay to diagnose and quantify KRAS and BRAF mutation. PloS one, 7(4), e36084.

- Morlan, J., Baker, J., \& Sinicropi, D. (2009). Mutation detection by real-time PCR: a simple, robust and highly selective method. PloS one, 4(2), e4584.

- Nielsen, P. E. (2010). Peptide nucleic acids (PNA) in chemical biology and drug discovery. Chemistry \& biodiversity, 7(4), 786-804.

- Ogino, S., Shima, K., Meyerhardt, J. A., McCleary, N. J., Ng, K., Hollis, D., ... \& Fuchs, C. S. (2012). Predictive and prognostic roles of BRAF mutation in stage III colon cancer: results from intergroup trial CALGB 89803. Clinical Cancer Research, 18(3), 890-900.

- Ray, A., \& Nordén, B. (2000). Peptide nucleic acid (PNA): its medical and biotechnical applications and promise for the future. The FASEB Journal, 14(9), 1041-1060.

- Roth, A. D., Tejpar, S., Delorenzi, M., Yan, P., Fiocca, R., Klingbiel, D., ... \& Bosman, F.
(2010). Prognostic role of KRAS and BRAF in stage II and III resected colon cancer: results of the translational study on the PETACC-3, EORTC 40993, SAKK 60-00 trial. Journal of Clinical Oncology, 28(3), 466-474.

- Scaltriti, M., \& Baselga, J. (2006). The epidermal growth factor receptor pathway: a model for targeted therapy. Clinical Cancer Research, 12(18), 5268-5272.

- Schirripa, M., Cremolini, C., Loupakis, F., Morvillo, M., Bergamo, F., Zoratto, F., ... \& Falcone, A. (2014). Role of NRAS mutations as prognostic and predictive markers in metastatic colorectal cancer. International Journal of Cancer.

- Skronski, M., Tanaka, T., Szpechcinski, A., Langfort, R., Orlowski, T., Hagiwara, K., \& Chorostowska-Wynimko, J. (2011). Evaluation of highly sensitive PNA-LNA PCR clamp method for EGFR L858R mutation detection in lung adenocarcinoma patients. European Respiratory Journal, 38(Suppl 55), p1957.

- Tougeron, D., Cortes, U., Ferru, A., Villalva, C., Silvain, C., Tourani, J. M., ... \& Karayan-Tapon, L. (2013). Epidermal growth factor receptor (EGFR) and KRAS mutations during chemotherapy plus anti-EGFR monoclonal antibody treatment in metastatic colorectal cancer. Cancer chemotherapy and pharmacology,72(2), 397-403.

- Valtorta, E., Misale, S., Sartore-Bianchi, A., Nagtegaal, I. D., Paraf, F., Lauricella, C., ... \& Nicolantonio, F. (2013). KRAS gene amplification in colorectal cancer and impact on response to EGFR-targeted therapy.International Journal of Cancer, 133(5), 1259-1265.

- Vaughn, C. P., ZoBell, S. D., Furtado, L. V., Baker, C. L., \& Samowitz, W. S. (2011). Frequency of KRAS, BRAF, and NRAS mutations in colorectal cancer.Genes, Chromosomes and Cancer, 50(5), 307-312. 